\title{
Neutronic benchmark of the molten salt fast reactor in the frame of the EVOL and MARS collaborative projects
}

\author{
Mariya Brovchenko ${ }^{1}$, Jan-Leen Kloosterman ${ }^{2}$, Lelio Luzzi $^{3}$, Elsa Merle ${ }^{1, *}$, Daniel Heuer $^{1}$, Axel Laureau ${ }^{1}$, \\ Olga Feynberg ${ }^{4}$, Victor Ignatiev ${ }^{4}$, Manuele Aufiero ${ }^{3}$, Antonio Cammi ${ }^{3}$, Carlo Fiorina ${ }^{3}$, Fabio Alcaro ${ }^{5}$, \\ Sandra Dulla ${ }^{5}$, Piero Ravetto ${ }^{5}$, Lodewijk Frima ${ }^{2}$, Danny Lathouwers ${ }^{2}$, and Bruno Merk ${ }^{6}$ \\ ${ }^{1}$ CNRS-IN2P3-LPSC, Université Grenoble Alpes, Grenoble, France \\ 2 TU Delft, Delft, The Netherlands \\ ${ }^{3}$ Politecnico di Milano, Milano, Italy \\ ${ }^{4}$ Kurchatov Institute, Moscow, Russia \\ ${ }^{5}$ Politecnico di Torino, Torino, Italy \\ ${ }^{6}$ Helmholtz-Zentrum Dresden-Rossendorf, Dresden, Germany
}

Received: 30 August 2018 / Received in final form: 23 October 2018 / Accepted: 17 December 2018

\begin{abstract}
This paper describes the neutronic benchmarks and the results obtained by the various participants of the FP7 project EVOL and the ROSATOM project MARS. The aim of the benchmarks was two-fold: first to verify and validate each of the code packages of the project partners, adapted for liquid-fueled reactors, and second to check the dependence of the core characteristics to nuclear data set for application on a molten salt fast reactor (MSFR). The MSFR operates with the thorium fuel cycle and can be started with ${ }^{233} \mathrm{U}$-enriched U and/or TRU elements as initial fissile load. All three compositions were covered by the present benchmark. The calculations have confirmed that the MSFR has very favorable characteristics not present in other Gen4 fast reactors, like strong negative temperature and void reactivity coefficients, a low-fissile inventory, a reduced longlived waste production and its burning capacities of nuclear waste produced in currently operational reactors.
\end{abstract}

\section{Introduction}

The molten salt reactor (MSR) concept is one of the reference nuclear systems identified by the Generation-IV International Forum (GIF) [1]. Since 2004, the National Centre for Scientific Research (CNRS, Grenoble-France) has focused R\&D efforts on the development of a new MSR concept called the molten salt fast reactor (MSFR). The MSFR, with a fast neutron spectrum and operated in the thorium fuel cycle, may be started either with ${ }^{233} \mathrm{U}$, enriched $U$ and/or TRU elements as initial fissile load. This concept has been recognized as a long-term alternative to solid-fuelled fast neutron systems with a unique potential (negative temperature and void coefficients, lower fissile inventory, no initial criticality reserve, simplified fuel cycle, wastes reduction, etc.).

The Euratom FP7 project EVOL (Evaluation and Viability of Liquid Fuel Fast Reactor Systems) has been carried out since 2011 in collaboration with Russian research organizations cooperating in the ROSATOM

\footnotetext{
* e-mail: elsa.merle@lpsc.in2p3.fr
}

project named MARS (Minor Actinides Recycling in Molten Salt). The common objective of these projects is to propose a conceptual design of MSFR as the best system configuration - resulting from physical, chemical and material studies - for the reactor core, the reprocessing unit and waste conditioning. The first objective of the work package "Design\&Safety" in EVOL addresses the improvement of the core geometry of the MSFR. A comparison of the different numerical tools for the reactor analysis used by the partners of the EVOL and MARS projects has been realized. This evaluation comprises two sets of benchmarks, of which the first one focuses on the neutronics aspects (both static and dynamic) of the reactor.

The neutronic benchmark was carried out using different reactor working parameters with two aims: first, to compare the results of the different codes at various working conditions. Second, to use these results to perform an initial optimization of the core parameters that would allow defining a reference design to be used for the second set of benchmark studies. Special emphasis was given to the adequacy of the codes to correctly account for the effects of the presence of a liquid fuel and a fast neutron spectrum in the core of the MSFR. 
In this article, Section 2 provides the characteristics of the MSFR used in the studies (core and the main fuel circuit systems). Section 3 provides the details of the neutronic benchmark. Finally, Section 4 presents the results from both static and evolution reactor calculations.

\section{MSFR presentation}

Starting from the Oak-Ridge National Laboratory Molten Salt Breeder Reactor project [2], the innovative MSFR concept has been proposed, resulting from extensive parametric studies in which various core arrangements, reprocessing performances and salt compositions were investigated with a view to the deployment of a thoriumbased reactor fleet on a worldwide scale [3-9] . The primary feature of the MSFR concept versus that of other older MSR designs is the absence of graphite moderator in the core (graphite-free core), resulting in a breeder reactor with a fast neutron spectrum and operated in the thorium fuel cycle as described below. The MSFR has been recognized as a long-term alternative to solid-fuelled fast neutron systems with a unique potential (excellent safety coefficients, small fissile inventory, no need for surplus reactivity, simplified fuel cycle, etc.) and has thus been officially selected for further studies by the Generation IV International Forum since 2008 [1,10-14].

\subsection{Concept overview}

The reference MSFR is a $3000 \mathrm{MW}_{\text {th }}$ reactor with a fast neutron spectrum and based on the thorium fuel cycle as previously mentioned. In the MSFR, the liquid fuel processing is an integral part of the reactor where a small fraction of the molten salt ( $40 \mathrm{~L} /$ day) is set aside to be processed for fission product removal and then returned to the reactor. This is fundamentally different from a solidfuelled reactor where separate facilities produce the solid fuel and process the spent nuclear fuel (SNF). The MSFR can be operated with widely varying fuel compositions, thanks to its online fuel control and flexible fuel processing: its initial fissile load may comprise ${ }^{233} \mathrm{U}$, ${ }^{235} \mathrm{U}$-enriched natural uranium (between $5 \%$ and $30 \%$ ), or the transuranic (TRU) elements currently produced by PWRs.

The MSFR plant includes three main circuits involved in power generation: the fuel circuit, the intermediate circuit and the power conversion circuit. The fuel circuit is defined as the circuit containing the fuel salt during power generation and includes the core cavity and the cooling sectors allowing the heat extraction. The nuclear fission reactions take place in the cavity where a critical mass of the flowing fuel salt is reached. The core cavity can be decomposed in three free volumes: the active core, the upper extraction volume and the lower injection volume. The salt's thermalhydraulic behavior is closely coupled to its neutronic behavior, because the salt's circulating time $(4 \mathrm{~s})$ and the lifetime of the precursors (around 10s) are on the same order of magnitude. A sketch of the fuel circuit layout is presented in Figure 1.

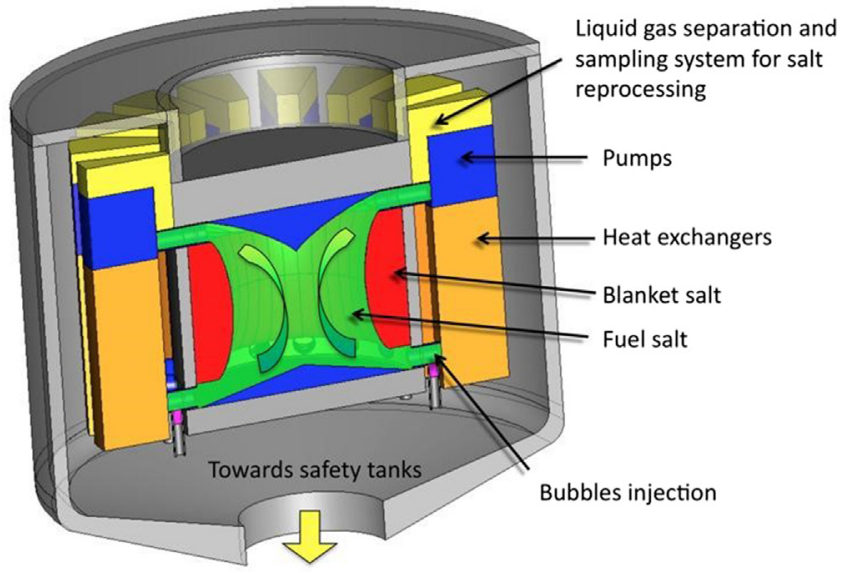

Fig. 1. Conceptual design of the MSFR [15].

Optimization studies have been performed prior to the beginning of the EVOL project, based on neutronic considerations (feedback coefficients and breeding capability), material damages and heat extraction efficiency, which resulted in MSFR configurations with a total fuel salt volume of $18 \mathrm{~m}^{3}$, half of the salt $\left(9 \mathrm{~m}^{3}\right)$ located in the core and half in the external circuits as explained above. Based on these preliminary studies and for the purpose of the current analysis, the core cavity was assumed to have a cylindrical shape with a height to diameter ratio $(H / D)$ equal 1 (to minimize the neutron leakage and thus to improve the breeding ratio). A more complete description of the design is given in the following sections.

\subsection{Systems description of the MSFR fuel circuit}

As mentioned, during normal operation, the fuel salt circulates in the core and in 16 external modules, so called fuel loops. Each of them contains a pump, a heat exchanger and a bubbling system (external modules). The time circulation of the fuel salt is on the order of a few seconds, depending on the specific core power and the salt temperature rise $(\Delta T)$ in the core. The principal reactor systems, which have an impact on the core optimization, will be discussed in detail in the following paragraphs.

- Core: The active core region is defined as the salt volume where most nuclear fissions take place. It includes the flowing salt in the central cavity, the injection zone (bottom part of the core) and the extraction zone (top part of the core). In the MSFR core, there is no solid moderator or any internal support structure except for the wall materials. As previously mentioned, the reference concept is designed for a nominal power of $3 \mathrm{GW}_{\text {th }}$, with a salt temperature rise preliminary fixed at $\Delta T=100 \mathrm{~K}$. The operating temperatures chosen in the initial simulations were $650^{\circ} \mathrm{C}$ (inlet temperature) and $750^{\circ} \mathrm{C}$ (outlet temperature). The lower limit is set by to the salt's melting point $\left(565^{\circ} \mathrm{C}\right)$, while the upper limit is imposed by the structural materials performance (limit around $800^{\circ} \mathrm{C}$ ). The core working parameters were defined after performing various parametric studies seeking for low neutron losses, low reflector irradiation and minimal fissile inventory, while maintaining a fuel 
salt volume in the heat exchangers large enough to ensure that salt cooling by $\Delta T=-100 \mathrm{~K}$ is feasible. The resulting core shape is roughly a cylinder, with $1 / 2$ of the entire salt volume inside the core, the rest being located in the external fuel loops. This core geometry has to be further optimized to guarantee a stable flow in the core.

- Fuel salt: The choice of the fuel salt composition relies on several parametric reactor studies (chemical and neutronic considerations, burning capabilities, safety coefficients and deployment capabilities). The optimal fuel salt composition is a binary fluoride salt, composed of $\mathrm{LiF}$ enriched in ${ }^{7} \mathrm{Li}$ to $99.995 \%$ and a heavy nuclei (HN) mixture initially composed of fertile thorium and fissile matter. This salt composition leads to a fast neutron spectrum in the core. With a melting temperature of $565^{\circ} \mathrm{C}$, the mean operating temperature has been chosen at around $700{ }^{\circ} \mathrm{C}$ (see above). The actinides produced during reactor operation are soluble in the fluoride salt within the solubility limit of valence 3 elements. The fission products created during operation can be soluble or insoluble in the salt. To maintain the physicochemical and neutronic characteristics of the salt, it is necessary to clean the salt, i.e. to extract the fission products. It is important to stress that due to the fast neutron spectrum of the MSFR, the impact of the fission products on the neutron economy is relatively small and thus the control of the physicochemical properties is clearly the main aim of the reprocessing unit. The temperature of the salt depends strongly on the operation of the pumps and the cooling in the heat exchangers.

- Upper and lower reflectors: The lower and upper walls of the core are neutronic reflectors. A NiCrW Hastelloy has been selected (see Sect. 2.3.2 for its composition) as a structural material candidate for the reflector walls and for all other internal walls in contact with the fuel salt. The upper reflector is submitted to mechanical, thermal (the fuel salt's mean temperature in the extraction area is around $750{ }^{\circ} \mathrm{C}$ with possible spatial and time-dependent fluctuations) and radiation constraints. The combination of high temperature and high radiation levels seems to be the biggest challenge for the proposed alloy so that the surface of the upper reflector may require a thermal protection. Due to the significant lower inlet temperature, the lower reflector is under reduced thermal stress. Optimized shapes of these reflectors will be studied to ensure the most stable thermal flow in the core.

- Fertile blanket: This component serves as radial reflector and as a neutron shield to protect the external components of the fuel loops (pipes, heat exchangers). In addition to this protection function, the fertile blanket is used to improve the breeding capabilities of the reactor. The walls of the blanket containment are made of a Nibased alloy for corrosion resistance and have an external layer of $\mathrm{B}_{4} \mathrm{C}$ on the outer wall to further reinforce the neutronic shielding. The salt in the blanket is of the same type as the one in the core but with $22.5 \mathrm{~mol} \%$ of Th and without any initial fissile material. Since the thorium present in the fertile salt is exposed to the core neutron flux, it will generate the ${ }^{233} \mathrm{U}$ fissile element. A small fraction of the ${ }^{233} \mathrm{U}$ produced in the blanket will fission so that fission products are produced in the blanket and will need to be extracted. In addition, the power arising from the ${ }^{233} \mathrm{U}$ fissions (13 MW) and from the captures on thorium (24 MW) will heat up the fertile salt in the blanket. It has been found that this heat cannot be evacuated through the blanket walls by a natural convection mechanism of the fertile salt. Therefore, a fertile blanket external cooling system will be necessary. If breeding is not required, the MSFR design could be simplified by replacing the fertile blanket by an inert reflector, identical to the axial reflectors. Optimized shapes of the fertile blanket may also be studied to improve the thermal flow in the core.

- Cooling/recirculation loops $(\times \mathbf{1 6})$ : Each of the 16 cooling/recirculation loop is composed of one heat exchanger (HX) and one pump (see below).

- Heat exchanger $(\times 16)$ : Each heat exchanger $(\mathrm{HX})$ unit has to extract about $187 \mathrm{MW}$ during normal operation. The HX design is challenging since a very compact design is needed (to reduce the volume of the fuel salt outside the core) but on the other hand the maximum compactness achievable has to be limited by considerations on the HX pressure drop, the maximum velocity allowed for the salt (erosion) and the thermodynamic properties of the working fluids. A preliminary design has been developed based on a plate heat exchanger type, which allows for a reasonable compromise between compactness (exchange surface) and pressure drop. This preliminary design is adequate for the purpose of the current benchmarks but will require further studies (in particular related to the geometry, materials and fabrication) to allow for a better optimization. The design of this component impacts the heating $\Delta T$ in the core when both reactor power and total fuel volume are fixed.

- Pump (×16): The salt is circulated in the reactor by 16 pumps located in each of the fuel loops. The fuel salt flow rate is about $0.28 \mathrm{~m}^{3} / \mathrm{s}$ to guarantee an adequate temperature rise in the core for the current core power level. The power of the pumps has an impact on the circulation time of the salt and thus on the heating in the core.

- Reactor vessel: The core and the reactor systems (components of fuel loops such as pipes, pumps, HX, etc.) described before are contained inside a reactor vessel that is filled with an inert gas (argon). As in the original experimental reactor MSRE, the inert gas has a double function: it is used to cool the reactor components by maintaining the gas temperature at around $400{ }^{\circ} \mathrm{C}$; and it allows for sampling to early detect a possible salt leak. Note that fixing the gas temperature at $400^{\circ} \mathrm{C}$ will guarantee that in the event of a small fuel salt leak, the salt should solidify since its melting temperature is equal to $565{ }^{\circ} \mathrm{C}$. The reactor vessel parameters (geometrical and material) do not directly impact the core performance (and thus are not needed for the optimization) but will be necessary for the safety analysis.

An integrated geometry of the fuel circuit $[15,16]$ has been developed in order to prevent the risk of fuel leakages highlighted by preliminary safety and optimization studies. 
Table 1. Physicochemical properties used for the fuel and fertile salt in the Benchmark, measured for the salt $78 \mathrm{~mol} \%$ $\mathrm{LiF}-22 \mathrm{~mol} \% \mathrm{ThF}_{4}[29]$.

\begin{tabular}{llll}
\hline & Formula & Value at $700{ }^{\circ} \mathrm{C}$ & Validity range, ${ }^{\circ} \mathrm{C}$ \\
\hline Density $\rho\left(\mathrm{g} / \mathrm{cm}^{3}\right)$ & $4.094-8.82 \times 10^{-4}\left(T_{(\mathrm{K})}-1008\right)$ & 4.1249 & $620-850$ \\
Kinematic viscosity $\nu\left(\mathrm{m}^{2} / \mathrm{s}\right)$ & $5.54 \times 10^{-8} \exp \left\{3689 / T_{(\mathrm{K})}\right\}$ & $2.46 \times 10^{-6}$ & $625-846$ \\
Dynamic viscosity $\mu(\mathrm{Pas})$ & $\rho\left(\mathrm{g} / \mathrm{cm}^{3}\right) \times 5.54 \times 10^{-5} \exp \left\{3689 / T_{(\mathrm{K})}\right\}$ & $10.1 \times 10^{-3}$ & $625-846$ \\
Thermal conductivity $\lambda(\mathrm{W} /(\mathrm{m} \mathrm{K}))$ & $0.928+8.397 \times 10^{-5} \times T_{(\mathrm{K})}$ & 1.0097 & $618-747$ \\
Heat capacity $C_{\mathrm{p}}(\mathrm{J} /(\mathrm{kg} \mathrm{K}))$ & $\left(-1.111+0.00278 \times T_{(\mathrm{K})}\right) \times 10^{3}$ & 1594 & $594-634^{\mathrm{a}}$ \\
\hline
\end{tabular}

${ }^{\text {a }}$ In fact, we have to extrapolate the formulas up to $700{ }^{\circ} \mathrm{C}$.

Table 2. Composition (at.\%) of the Ni-based alloy considered for the simulation of the structural materials of the core.

\begin{tabular}{|c|c|c|c|c|c|c|c|c|c|c|c|c|}
\hline $\mathrm{Ni}$ & $\mathrm{W}$ & $\mathrm{Cr}$ & Mo & $\mathrm{Fe}$ & $\mathrm{Ti}$ & $\mathrm{C}$ & $\mathrm{Mn}$ & $\mathrm{Si}$ & $\mathrm{Al}$ & B & $\mathrm{P}$ & $\mathrm{S}$ \\
\hline 79.432 & 9.976 & 8.014 & 0.736 & 0.632 & 0.295 & 0.294 & 0.257 & 0.252 & 0.052 & 0.033 & 0.023 & 0.004 \\
\hline
\end{tabular}

\subsection{Data used for the simulations of the MSFR}

2.3.1 Physicochemical properties of the molten salts used in the MSFR

New measurements of the physicochemical properties of fluoride salts have been performed in the framework of the MARS and the ISTC \#3749 projects [17], the properties for a salt of $\mathrm{LiF}$ (78 $\left.\mathrm{mol}_{\mathrm{C}}\right)-\mathrm{ThF}_{4}(22 \mathrm{~mol} \%)$ are listed in Table 1. The third column summarizes the values used in these studies, at a mean temperature of $700^{\circ} \mathrm{C}$ (halfway between the low and the high operating temperatures). Because fission products and new heavy nuclei are produced in the salt during reactor operation up to some mole\% only, we have considered they do not impact these salt physicochemical properties. The same data are used in the simulations for the fertile salt.

\subsubsection{Structural materials}

The reflectors are made of a Ni-based alloy [18]. The density of the Ni-based alloy, whose composition is detailed in Table 2 , is equal to $10 \mathrm{~g} / \mathrm{cm}^{3}$. This material will not be exposed to a high neutron flux since there is no matter in the high flux area in the MSFR; hence, the choice of its composition is not too constrained. Preliminary studies of the irradiation damages have been performed in the frame of the EVOL project [19] and in previous collaborations [20]. A segmented geometry of the MSFR core is currently being defined in the frame of the SAMOFAR (Safety Assessment of the MOlten salt FAst Reactor) project of the Horizon2020 Euratom program, to simplify the maintenance operations as for the replacement of the wall between the fuel salt and the fertile salt if necessary.

Concerning the neutronics protection, we have considered the composition of natural boron: $19.8 \%$ of ${ }^{10} \mathrm{~B}$ and $80.2 \%$ of ${ }^{11} \mathrm{~B}$. The $\mathrm{B}_{4} \mathrm{C}$ density is set to $2.52 \mathrm{~g} / \mathrm{cm}^{3}$.

\section{Neutronic benchmark of the MSFR: presentation}

A first benchmark has been defined on a simple geometry to compare all neutronic calculations and check the effects of all possible assumptions. The choice of a simple geometry allows saving computer time and being able to compare all code solutions and all assumptions. The knowledge from this starting point is crucial to interpret follow-up results, obtained from more complex geometries. Working on such "real" geometries and design is the main final objective of EVOL.

The neutronic benchmark was thus carried out using different reactor working parameters with two aims: first, to compare the results of the different codes at various operating conditions. Second, to use these results to perform an initial optimization of the core parameters that would allow defining a reference design to be used for the second set of benchmark studies. Special emphasis was given in the neutronic benchmark to the adequacy of the codes to correctly account for the effects of a liquid fuel and a fast neutron spectrum.

\subsection{Description of the neutronic benchmark}

\subsubsection{Core geometry used in the benchmark}

As shown in Figure 2, the core has a cylindrical shape with its diameter equal to its height filled with a circulating fuel salt. The core is composed of three volumes: the active core, the upper plenum and the lower plenum. The fuel salt considered in the simulations is a binary salt, $\mathrm{LiF}-$ (Heavy Nuclei) $\mathrm{F}_{4}$, whose $(\mathrm{HN}) \mathrm{F}_{4}$ proportion is set at $22.5 \mathrm{~mol} \%$ (eutectic point), corresponding to a melting temperature of $565^{\circ} \mathrm{C}$. The choice of this fuel salt composition relies on many systematic studies (influence of the chemical reprocessing on the neutronic behavior, burning capabilities, deterministic safety evaluation and deployment capabilities). This salt composition leads to a fast neutron spectrum in the core. 



Fig. 2. Left: Simplified to scale vertical scheme of the MSFR system including the core, blanket and fuel heat exchangers (IHX). Right: Model of the core as used for the neutronic simulations (dimensions given in $\mathrm{mm}$ ) with the fuel salt (yellow), the fertile salt (pink), the $\mathrm{B}_{4} \mathrm{C}$ protection (orange) and the upper/lower reflectors and $20 \mathrm{~mm}$ thick walls in Ni-based allow (blue).

Table 3. Characteristics of the MSFR simulated in the neutronics benchmark.

\begin{tabular}{|c|c|c|c|c|c|}
\hline Thermal power (MWth) & \multicolumn{5}{|l|}{3000} \\
\hline Electric power (MWe) & \multicolumn{5}{|l|}{1500} \\
\hline Fuel molten salt initial composition (mol\%) & \multicolumn{5}{|c|}{ 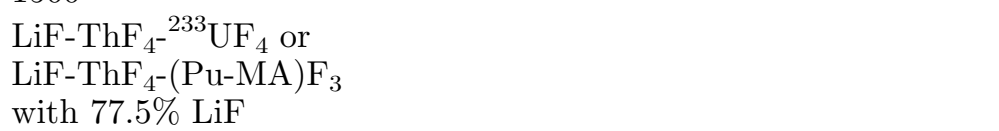 } \\
\hline $\begin{array}{l}\text { Fertile blanket molten salt initial } \\
\text { composition }(\mathrm{mol} \%)\end{array}$ & \multicolumn{5}{|c|}{$\mathrm{LiF}_{-} \mathrm{ThF}_{4}(77.5-22.5 \%)$} \\
\hline Melting point $\left({ }^{\circ} \mathrm{C}\right)$ & \multicolumn{5}{|l|}{565} \\
\hline Inlet/outlet operating temperature $\left({ }^{\circ} \mathrm{C}\right)$ & \multicolumn{5}{|c|}{$650-750$} \\
\hline \multirow[t]{6}{*}{ Initial inventory $(\mathrm{kg})$} & \multicolumn{2}{|c|}{${ }^{233} \mathrm{U}$-started MSFR } & \multicolumn{3}{|c|}{ TRU-started MSFR } \\
\hline & & ${ }^{233} \mathrm{U}$ & & Acti & \\
\hline & 38300 & 5060 & 30600 & $\mathrm{Pu}$ & 11200 \\
\hline & & & & $\mathrm{Np}$ & 800 \\
\hline & & & & $\mathrm{Am}$ & 680 \\
\hline & & & & $\mathrm{Cm}$ & 115 \\
\hline Density $\left(\mathrm{g} / \mathrm{cm}^{3}\right)$ & \multicolumn{5}{|l|}{4.1249} \\
\hline Dilatation coefficient $\left(\mathrm{g} /\left(\mathrm{cm}^{3} \mathrm{~K}\right)\right)[29]$ & \multicolumn{5}{|c|}{$8.82 \times 10^{-4}$} \\
\hline Core dimensions $(\mathrm{m})$ & \multicolumn{5}{|c|}{ Radius: 1.1275} \\
\hline & \multicolumn{5}{|c|}{ Height: 2.255} \\
\hline Fuel salt volume $\left(\mathrm{m}^{3}\right)$ & \multicolumn{5}{|c|}{18} \\
\hline & \multicolumn{5}{|c|}{9 out of the core } \\
\hline & \multicolumn{5}{|c|}{9 in the core } \\
\hline Blanket salt volume $\left(\mathrm{m}^{3}\right)$ & \multicolumn{5}{|c|}{7.3} \\
\hline Fuel salt cycle time in the system (s) & \multicolumn{5}{|l|}{4.0} \\
\hline
\end{tabular}

As mentioned previously, the radial reflector is a fertile blanket ( $\sim 50 \mathrm{~cm}$ thick) filled with $7.3 \mathrm{~m}^{3}$ of a fertile salt $\mathrm{LiF}_{-} \mathrm{ThF}_{4}$ with molar $22.5 \%$ of ${ }^{232} \mathrm{Th}$. This fertile blanket improves the global breeding ratio of the reactor, thanks to a ${ }^{233} \mathrm{U}$ extraction within 6 months, i.e. $100 \%$ of the ${ }^{233} \mathrm{U}$ produced in the blanket is extracted in 192 days $(40 \mathrm{~L} /$ day as shown in the lower part of Fig. 2). This fertile blanket is surrounded by a $20 \mathrm{~cm}$ thick neutronic protection of $\mathrm{B}_{4} \mathrm{C}$, 
Table 4. Proportion of transuranic nuclei in UOX fuel after one use in PWR without multirecycling (burn-up of $60 \mathrm{GWd} /$ ton) and after $5 \mathrm{yr}$ of storage.

\begin{tabular}{ll}
\hline Isotope & $\begin{array}{l}\text { Proportion in the } \\
\operatorname{mix}(\operatorname{mol} \%)\end{array}$ \\
\hline $\mathrm{Np} \mathrm{237}$ & 6.3 \\
$\mathrm{Pu} 238$ & 2.7 \\
$\mathrm{Pu} 239$ & 45.9 \\
$\mathrm{Pu} 240$ & 21.5 \\
$\mathrm{Pu} 241$ & 10.7 \\
$\mathrm{Pu} 242$ & 6.7 \\
$\mathrm{Am} 241$ & 3.4 \\
$\mathrm{Am} 243$ & 1.9 \\
$\mathrm{Cm} 244$ & 0.8 \\
$\mathrm{Cm} 245$ & 0.1 \\
\hline
\end{tabular}

which absorbs the remaining neutrons and protects the heat exchangers. The thickness of this $\mathrm{B}_{4} \mathrm{C}$ protection has been determined so that the neutron flux from the core is negligible compared to the flux of delayed neutrons emitted in the heat exchangers.

The radial blanket geometry is an angular section torus $188 \mathrm{~cm}$ high and $50 \mathrm{~cm}$ thick. The $2 \mathrm{~cm}$ thick walls are made of Ni-based alloy (see composition in Tab. 2). A single volume of fertile salt is considered, homogenous and cooled to a mean temperature of $650^{\circ} \mathrm{C}$. A temperature variation of the fertile salt of around $30^{\circ} \mathrm{C}$ between the bottom and the top of the fertile blanket may be introduced to check its low impact on the reactor evolution.

\subsubsection{Fuel salt initial composition}

The core contains a fluoride fuel salt, composed of $77.5 \mathrm{~mol} \%$ of $\mathrm{LiF}$ enriched in ${ }^{7} \mathrm{Li}$ (99.995 at.\%) and $22.5 \mathrm{~mol} \%$ of heavy nuclei (HN) among the fissile element. This HN fraction is kept constant during reactor evolution, the produced FPs replacing an equivalent proportion of the lithium. The neutronics benchmark focuses on the ${ }^{233} \mathrm{U}$-started and the TRU-started MSFR. Dedicated studies have been performed in the frame of EVOL to optimize the initial fuel salt compositions, based on neutronics and chemical and material issues $[18,20]$.

\section{${ }^{233} \mathrm{U}$-started MSFR}

As detailed in Table 3 , in this case the initial fuel salt is composed of $\mathrm{LiF}_{-} \mathrm{ThF}_{4^{-}}{ }^{233} \mathrm{UF}_{3}$, the initial fraction of ${ }^{233} \mathrm{U}$ being adjusted to have an exactly critical reactor.

\section{TRU-started MSFR}

The initial fuel salt is composed of $\mathrm{LiF}_{-}-\mathrm{ThF}_{4}-(\mathrm{TRU}) \mathrm{F}_{3}$. More precisely, the reference MSFR is started with a TRU mix of $87.5 \%$ of $\mathrm{Pu}\left({ }^{238} \mathrm{Pu} 2.7 \%,{ }^{239} \mathrm{Pu} 45.9 \%,{ }^{240} \mathrm{Pu} 21.5 \%\right.$, ${ }^{241} \mathrm{Pu} 10.7 \%$ and ${ }^{242} \mathrm{Pu} 6.7 \%$ ), $6.3 \%$ of Np, $5.3 \%$ of Am and $0.9 \%$ of $\mathrm{Cm}$, as listed in Table 4 and corresponding to the transuranic elements contained in SNF from UOX fuel after use in a standard LWR with burn-up of $60 \mathrm{GWd} /$ ton and after $5 \mathrm{yr}$ of storage. The amounts of TRU elements initially loaded in the TRU-started MSFR are given in Table 4.

\subsubsection{Fuel salt reprocessing considered for the evolution} calculations

As displayed in Figure 3, the salt management combines a salt control unit, an online gaseous extraction system and an offline lanthanide extraction component by pyrochemistry.

The gaseous extraction system, where helium bubbles are injected into the core, removes all nonsoluble fission products (noble metals and gaseous fission products). This online bubbling extraction has a removal period $T_{1 / 2}=30 \mathrm{~s}$ in the simulations. The elements extracted by this system are the following: $Z=1,2,7,8,10,18,36,41,42,43,44,45$, $46,47,51,52,54$ and 86 [21].

A fraction of the salt is periodically withdrawn and reprocessed offline in order to extract the lanthanides before it is sent back to the core. The actinides are sent back to the core as soon as possible in order to be burnt. With the online control and adjustment part, the salt composition and properties are checked.

The rate at which this offline salt reprocessing is done depends on the desired breeding performance. In the reference simulations, we have fixed the reprocessing rate at $40 \mathrm{~L} /$ day whatever the fuel salt volume, i.e. the whole core is reprocessed in 450 days. In the simulation of the reactor evolution, this is taken into account through a $100 \%$ offline extraction of the following fission products in 450 days: $Z=30,31,32,33,34,35,37,38,39,40,48,49,50$, $53,55,56,57,58,59,60,61,62,63,64,65,66,67,68,69,70$.

Thanks to this simplified reprocessing scheme, even if not totally realistic, a stationary state may be reached during the reactor evolution.

The fission products of the fertile blanket are slowly removed, with a rate of $0.4 \mathrm{~L}$ of salt cleaned per day i.e. the whole fertile salt volume $\left(7.3 \mathrm{~m}^{3}\right)$ cleaned in 19250 days (52.7 yr) [15]. The actinides, mostly ${ }^{233} \mathrm{U}$, are extracted and then reinjected into the core at a rate of $40 \mathrm{~L}$ of salt cleaned per day. Additionally, the gaseous fission products are extracted in the same way as in the core (see above).

\subsubsection{Delayed neutron precursors}

For all the calculations presented here, unless otherwise specified in Section 3.2, mean values of abundances for the neutron precursors (see Tab. 5) have been considered for fissions that are due to ${ }^{233} \mathrm{U}(90 \%)$ and ${ }^{235} \mathrm{U}(10 \%)$ with a spectrum located between a thermal and a fast one $(50 \%$ of thermal spectrum and $50 \%$ of fast spectrum) [22].

\subsection{Tools used for the neutronics and evolution calculations}

Since the partners of the EVOL and MARS projects use different numerical tools for the reactor analysis based on neutronic calculations, a comparative evaluation of the existing codes was necessary. The different numerical tools developed or used by the partners of the EVOL and MARS projects are listed in Table 6 , the first objective of the benchmark being to evaluate their adequacy to simulate the core of the MSFR, which combines both a liquid fuel and a fast neutron spectrum. 


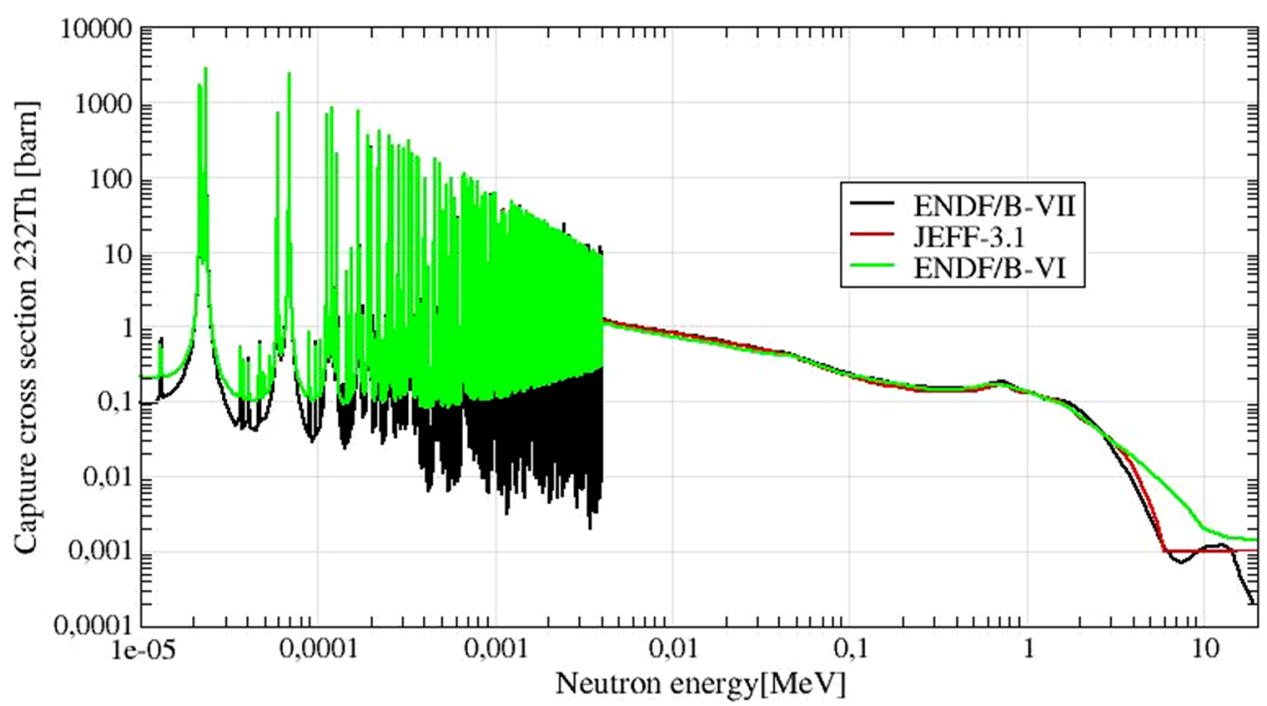

Fig. 3. $(n, \gamma)$ cross section of ${ }^{232}$ Th for the different databases used in the neutronic benchmark calculations.

Table 5. Abundances of seven delayed neutron precursors for two uranium isotopes.

\begin{tabular}{llllllll}
\hline Group & 1 & 2 & 3 & 4 & 5 & 6 & 7 \\
\hline $\begin{array}{l}\text { Precursor } \\
\text { Half-life (s) }\end{array}$ & ${ }^{87} \mathrm{Br}$ & ${ }^{137} \mathrm{I}$ & ${ }^{88} \mathrm{Br}$ & ${ }^{93} \mathrm{Rb}$ & ${ }^{139} \mathrm{I}$ & ${ }^{91} \mathrm{Br}$ & ${ }^{96} \mathrm{Rb}$ \\
$\begin{array}{l}\text { Abundances } \\
{ }^{233} \mathrm{U} \text { (fast) }\end{array}$ & 55.9 & 24.5 & 16.4 & 5.85 & 2.3 & 0.54 & 0.199 \\
${ }^{233} \mathrm{U}$ (thermal) & 0.0788 & 0.1666 & 0.1153 & 0.1985 & 0.3522 & 0.0633 & 0.0253 \\
${ }^{235} \mathrm{U}$ (fast) & 0.0787 & 0.1723 & 0.1355 & 0.1884 & 0.3435 & 0.0605 & 0.0211 \\
${ }^{235} \mathrm{U}$ (thermal) & 0.0339 & 0.1458 & 0.0847 & 0.1665 & 0.4069 & 0.1278 & 0.0344 \\
Mean value & 0.0321 & 0.1616 & 0.0752 & 0.1815 & 0.3969 & 0.1257 & 0.0270 \\
\hline
\end{tabular}

\section{Neutronic benchmark of the MSFR: results}

\subsection{Static calculations}

4.1.1 Effective reactivity $\left(k_{\text {eff }}\right)$ corresponding to the initial compositions provided

First, a calculation of the effective multiplication coefficient $k_{\text {eff }}$ for the compositions are provided in the benchmark and reminded in Table 7.

The results of this calculation (see Tab. 8) show some important discrepancies that may be understood by looking more deeply into the reaction rates corresponding to each reactor calculation. The uncertainty on $k$ corresponds to the statistical uncertainty for the stochastic tools. As can be concluded from Table 9 (for the ${ }^{233} \mathrm{U}$-started MSFR composition), the choice of the database impacts the results, especially for the capture rates of ${ }^{233} \mathrm{U}$ and ${ }^{232} \mathrm{Th}$. As shown in Figures 3 and 4 , the $(n, \gamma)$ cross sections of ${ }^{233} \mathrm{U}$ and ${ }^{232}$ Th show some noticeable discrepancies between the different databases.

Using JEFF-3.1 database, LPSC and POLIMI calculations are globally in good agreement even if some small discrepancies may be noticed on the ${ }^{6} \mathrm{Li}$ reaction rates.
4.1.2 Adjustment of the critical amount of initial fissile matter

The adjustments of the initial fissile amount have been performed either for $k_{\text {prompt }}=1$ or $k_{\text {eff }}=1$ depending on the partner, the precision $\Delta k$ corresponding to each evaluation being indicated in Table 10 for the ${ }^{233} \mathrm{U}$-started MSFR and in Table 11 for the TRU-started MSFR. Again, some differences are observed, especially for the ${ }^{233} \mathrm{U}$-started MSFR. Those are partly due to the different databases used for this evaluation by each partner, as already mentioned.

The critical inventories adjusted by each partner are quite similar despite the various calculation tools and databases used. We have to notice that the amount of ${ }^{233} \mathrm{U}$ is the most sensitive to these differences between the calculations, the differences on its evaluation being mainly due to the database used. In particular, the $(n, \gamma)$ cross sections of ${ }^{233} \mathrm{U}$ and ${ }^{232} \mathrm{Th}$ show some noticeable discrepancies between the different databases (see Figs. 3 and 4).

\subsubsection{Delayed neutron fraction}

In Tables 12-14, the following definitions are used: 
M. Brovchenko et al.: EPJ Nuclear Sci. Technol. 5, 2 (2019)

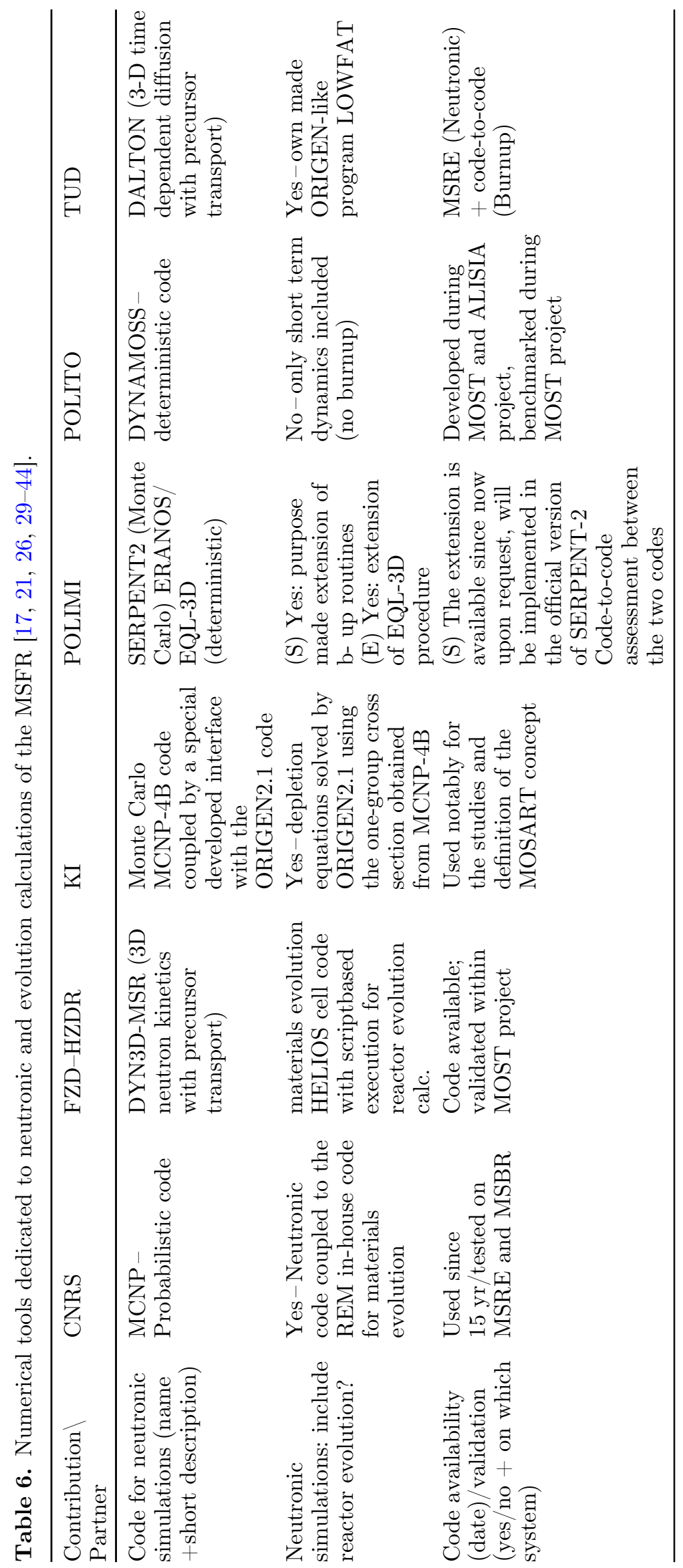


Table 7. Initial composition of the ${ }^{233} \mathrm{U}$-started and TRU-started MSFR as provided by LPSC for the benchmark calculations and used in the following except in Sections 4.2.1 and 4.2.2.



Table 8. Multiplication coefficient evaluation by different partners with different databases for initial composition given in Table 7.

\begin{tabular}{llllllll}
\hline Composition & LPSC & LPSC & POLITO & POLITO & POLIMI & POLIMI & POLIMI \\
& ENDF-B.6 & JEFF-3.1 & $\begin{array}{l}\text { analog } \\
\text { JEFF-3.1.1 }\end{array}$ & $\begin{array}{l}\text { Implicit } \\
\text { JEFF-3.1.1 }\end{array}$ & $\begin{array}{l}\text { SERPENT } \\
\text { JEFF-3.1 }\end{array}$ & $\begin{array}{l}\text { SERPENT } \\
\text { ENDF-B7 }\end{array}$ & $\begin{array}{l}\text { ERANOS } \\
\text { JEFF-3.1 }\end{array}$ \\
\hline${ }^{233}$ U-started & $\mathbf{1 . 0 2 1 4 1}$ & $\mathbf{0 . 9 7 6 2 8}$ & $\mathbf{0 . 9 9 2 1 1}$ & $\mathbf{0 . 9 9 2 0 6}$ & $\mathbf{0 . 9 9 4 0 6}$ & $\mathbf{0 . 9 8 3 0 1}$ & $\mathbf{1 . 0 1 7 0 7}$ \\
$\Delta k$ & $3 \mathrm{pcm}$ & $84 \mathrm{pcm}$ & $11 \mathrm{pcm}$ & $4.3 \mathrm{pcm}$ & $40 \mathrm{pcm}$ & $41 \mathrm{pcm}$ & - \\
TRU-started & $\mathbf{1 . 0 0 2 7 3}$ & $\mathbf{1 . 0 0 8 1 7}$ & $\mathbf{1 . 0 2 8 7 3}$ & $\mathbf{1 . 0 2 8 7 8}$ & $\mathbf{1 . 0 1 6 5 1}$ & $\mathbf{1 . 0 1 9 5 5}$ & $\mathbf{1 . 0 1 4 3}$ \\
$\Delta k$ & $2 \mathrm{pcm}$ & $72 \mathrm{pcm}$ & $12 \mathrm{pcm}$ & $4 \mathrm{pcm}$ & $44 \mathrm{pcm}$ & $45 \mathrm{pcm}$ & - \\
\hline
\end{tabular}

Table 9. Reaction rates in the fuel only, extracted from the evaluation by different partners with different databases for initial composition of ${ }^{233} \mathrm{U}$-started MSFR given in Table 7.

\begin{tabular}{lllll}
\hline Reaction rate $R=N \sigma \Phi(\mathrm{mol} /$ day $)$ & $\begin{array}{l}\text { LPSC } \\
\text { ENDF-B.6 }\end{array}$ & $\begin{array}{l}\text { LPSC } \\
\text { JEFF-3.1 }\end{array}$ & $\begin{array}{l}\text { POLITO } \\
\text { SERPENT } \\
\text { JEFF-3.1.1 }\end{array}$ & $\begin{array}{l}\text { POLIMI } \\
\text { SERPENT } \\
\text { JEFF-3.1 }\end{array}$ \\
\hline Mean flux $\Phi\left(n / \mathrm{cm}^{2} / \mathrm{s}\right)$ & $3.38 \times 10^{+15}$ & $3.57 \times 10^{+15}$ & $3.499 \times 10^{+15}$ & $3.56 \times 10^{+15}$ \\
& & & $\pm 2.1 \times 10^{+11}$ & 13.3 \\
Fission rate ${ }^{233} \mathrm{U}$ & 13.1 & 13.1 & & 1.37 \\
$(n, \gamma)$ rate ${ }^{233} \mathrm{U}$ & 1.56 & 1.36 & 0.24 \\
Fission rate ${ }^{232} \mathrm{Th}$ & 0.23 & 0.25 & 15.8 \\
$(n, \gamma)$ rate ${ }^{232} \mathrm{Th}$ & 15.1 & 15.9 & $1.9 \times 10^{-3}$ \\
$(\mathrm{n}, \mathrm{t})$ rate ${ }^{6} \mathrm{Li}$ & 0.154 & 0.157 & \\
$(n, p)$ rate ${ }^{6} \mathrm{Li}$ & $4.0 \times 10^{-5}$ & $3.9 \times 10^{-5}$ & & \\
$(n, \gamma)$ rate ${ }^{6} \mathrm{Li}$ & $5.9 \times 10^{-6}$ & $6.0 \times 10^{-6}$ & & $6.85 \times 10^{-3}$ \\
$(n, \gamma)$ rate ${ }^{7} \mathrm{Li}$ & $6.9 \times 10^{-3}$ & $7.6 \times 10^{-3}$ & & 0.12 \\
$(n, \gamma)$ rate ${ }^{19} \mathrm{~F}$ & 0.15 & 0.13 & & 0.29 \\
$(n, \alpha)$ rate ${ }^{19} \mathrm{~F}$ & 0.29 & 0.29 & & 17.29 \\
$(n, \gamma)$ rate total & 16.8 & 17.3 & & 13.55 \\
Fission rate total & 13.3 & 13.3 & & $0.1-5 \%$ \\
Statistic uncertainty & $<2 \%$ & $<2 \%$ & & \\
\hline
\end{tabular}


Table 10. ${ }^{233} \mathrm{U}$-started MSFR initial composition adjusted for $k_{\text {effective }}=1$ or $k_{\text {prompt }}=1$.

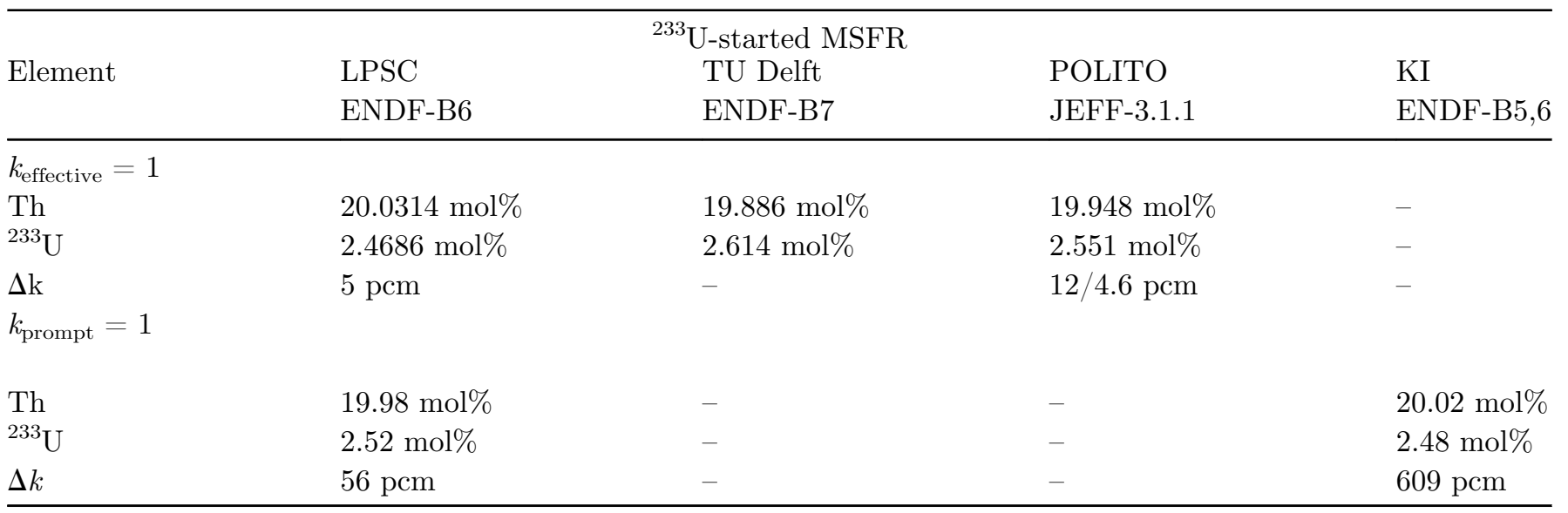

Table 11. TRU-started MSFR initial composition adjusted for $k_{\text {effective }}=1$ or $k_{\text {prompt }}=1$.

\begin{tabular}{llll}
\hline \multirow{2}{*}{ Element } & & TRU-started MSFR & KI \\
& LPSC & POLITO & ENDF-B5,6 \\
& $k_{\text {effective }}$ & JEFF-3.1.1 & $k_{\text {prompt }}$ \\
\hline $\mathrm{Th}$ & $16.068 \mathrm{~mol} \%$ & $k_{\text {effective }}$ & $16.2 \mathrm{~mol} \%$ \\
$\mathrm{Pu}$ & $5.628 \mathrm{~mol} \%$ & $16.3803 \mathrm{~mol} \%$ & $5.50 \mathrm{~mol} \%$ \\
$\mathrm{~Np}$ & $0.405 \mathrm{~mol} \%$ & $5.3547 \mathrm{~mol} \%$ & $0.400 \mathrm{~mol} \%$ \\
$\mathrm{Am}$ & $0.341 \mathrm{~mol} \%$ & $0.386 \mathrm{~mol} \%$ & $0.33 \mathrm{~mol} \%$ \\
$\mathrm{Cm}$ & $0.058 \mathrm{~mol} \%$ & $0.324 \mathrm{~mol} \%$ & $0.057 \mathrm{~mol} \%$ \\
$\Delta k$ & $54 \mathrm{pcm}$ & $0.055 \mathrm{~mol} \%$ & $153 \mathrm{pcm}$ \\
\hline
\end{tabular}

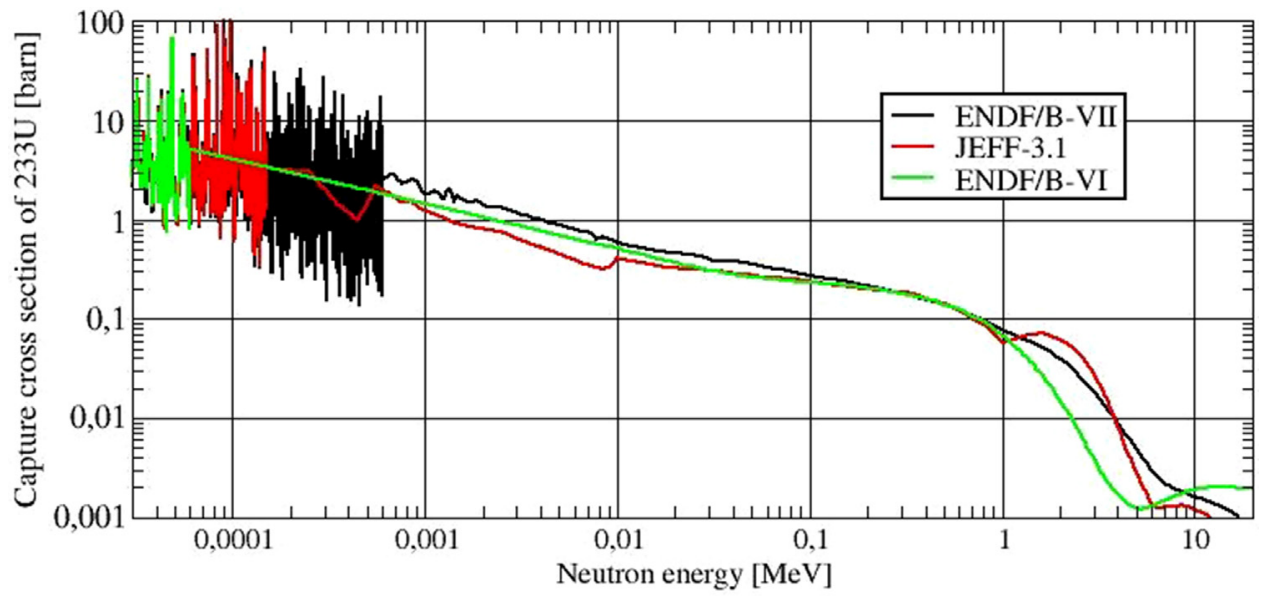

Fig. 4. Neutron capture cross section of ${ }^{233} \mathrm{U}$ for different databases.

- $\beta_{0}$ is the physical fraction of delayed neutrons.

- $\beta_{\text {eff }}$ is the fraction taking into account the importance of the delayed neutrons for the fission compared to the prompt neutrons $\left(E_{\mathrm{n}}^{\text {Delayed }}<E_{\mathrm{n}}^{\text {Prompt }}\right)$.

- $\beta_{\text {circ }}$ is the fraction of delayed neutrons accounting the motion of the fuel salt.
As expected, the TRU-started MSFR composition has the smallest fraction of delayed neutrons, while ${ }^{233}$ U-started MSFR composition the highest delayed neutron fraction according to all participants. It is clear that the circulation of the fuel salt has an important influence on the delayed neutron fraction. The correction 
Table 12. Initial delayed neutron fraction for the ${ }^{233} \mathrm{U}$-started MSFR.

\begin{tabular}{|c|c|c|c|c|c|c|c|}
\hline \multirow{2}{*}{$\begin{array}{l}{ }^{233} \mathrm{U} \text {-started } \\
\text { composition }\end{array}$} & \multirow{2}{*}{ LPSC ENDF/B6 } & \multirow{2}{*}{$\begin{array}{l}\text { POLITO JEFF-311 } \\
\text { (see Sect. 3.2.5) }\end{array}$} & \multicolumn{3}{|c|}{ POLIMI SERPENT } & \multirow{2}{*}{$\begin{array}{l}\text { POLIMI } \\
\text { ERANOS } \\
\text { JEFF-3.1 }\end{array}$} & \multirow{2}{*}{$\begin{array}{l}\text { TU Delft } \\
\text { ENDF-B7 }\end{array}$} \\
\hline & & & $\begin{array}{l}\text { JEF } \\
\text { Nominal } \\
\text { flow rate }\end{array}$ & $\begin{array}{l}\text {-3.1 } \\
\text { Uniform } \\
\text { sampling }\end{array}$ & ENDF-B7 & & \\
\hline$\beta_{0}(\mathrm{pcm})$ & 330 & $315.00 \pm 0.04$ & \multicolumn{2}{|c|}{310} & 325 & - & 310 \\
\hline$\beta_{\text {eff }}(\mathrm{pcm})$ & 320 & $305.00 \pm 0.76$ & \multicolumn{2}{|c|}{305} & 317.8 & 318.1 & 290 \\
\hline$\beta_{\text {circ }} / \beta_{\text {eff }}$ & 0.529 & 0.3837 & 0.479 & 0.407 & - & $0.540^{\mathrm{a}}$ & 0.430 \\
\hline$\underline{\beta}_{\text {circ }}(\mathrm{pcm})$ & 169.46 & 117.3 & 146 & 124 & - & $171.9^{\mathrm{a}}$ & 124.6 \\
\hline
\end{tabular}

${ }^{a}$ Values calculated with a simplified correction method and not with ERANOS.

Table 13. Initial delayed neutron fraction for the TRU-started.

\begin{tabular}{|c|c|c|c|c|c|c|c|c|}
\hline \multirow{3}{*}{$\begin{array}{l}\text { TRU-started } \\
\text { composition }\end{array}$} & \multirow{3}{*}{$\begin{array}{l}\text { LPSC } \\
\text { ENDF/B6 }\end{array}$} & \multirow{3}{*}{$\begin{array}{l}\text { POLITO JEFF-311 } \\
\text { (see Sect. 3.2.5) }\end{array}$} & \multicolumn{4}{|c|}{ POLIMI SERPENT } & \multirow{3}{*}{$\begin{array}{l}\text { POLIMI } \\
\text { ERANOS } \\
\text { JEFF-3.1 }\end{array}$} & \multirow{3}{*}{$\begin{array}{l}\text { TU Delft } \\
\text { ENDF/B7 }\end{array}$} \\
\hline & & & & JEFF-3. & & & & \\
\hline & & & $\begin{array}{l}\text { Nominal } \\
\text { rate }\end{array}$ & flow & $\begin{array}{l}\text { Uniform } \\
\text { sampling }\end{array}$ & $\mathrm{ENDF} / \mathrm{B} 7$ & & \\
\hline$\beta_{0}(\mathrm{pcm})$ & 342.6 & $343.00 \pm 0.05$ & & 334 & & 331 & - & - \\
\hline$\beta_{\text {eff }}(\mathrm{pcm})$ & 312.76 & $301.00 \pm 0.74$ & & 302 & & 301.9 & 302.1 & - \\
\hline$\beta_{\text {circ }} / \beta_{\text {eff }}$ & 0.529 & - & 0.487 & 0.391 & & - & $0.552^{\mathrm{a}}$ & - \\
\hline$\beta_{\text {circ }}(\mathrm{pcm})$ & 165.45 & - & 147 & 118 & & - & $166.7^{\mathrm{a}}$ & - \\
\hline
\end{tabular}

${ }^{a}$ Values calculated with a simplified correction method and not with ERANOS.

Table 14. Delayed neutron fraction of the MSFR at steady state.

\begin{tabular}{|c|c|c|c|c|c|c|c|}
\hline \multirow{3}{*}{$\begin{array}{l}\text { Steady-state } \\
\text { composition }\end{array}$} & \multirow{3}{*}{$\begin{array}{l}\text { LPSC ENDF/ } \\
\text { B6 }\end{array}$} & \multirow{3}{*}{$\begin{array}{l}\text { POLITO } \\
\text { JEFF-311 } \\
\text { (see Sect. 3.2.5) }\end{array}$} & \multicolumn{3}{|c|}{ POLIMI SERPENT } & \multirow{3}{*}{$\begin{array}{l}\text { POLIMI } \\
\text { ERANOS } \\
\text { JEFF-3.1 }\end{array}$} & \multirow{3}{*}{$\begin{array}{l}\text { TU Delft } \\
\text { ENDF/B7 }\end{array}$} \\
\hline & & & JEFF-3.1 & & & & \\
\hline & & & Nominal flow rate & $\begin{array}{l}\text { Uniform } \\
\text { sampling }\end{array}$ & $\mathrm{ENDF} / \mathrm{B} 7$ & & \\
\hline$\beta_{0}(\mathrm{pcm})$ & 359.7 & - & 331 & & 356 & - & 322 \\
\hline$\beta_{\text {eff }}(\mathrm{pcm})$ & 342.63 & - & 319.9 & & 340.8 & 334.2 & 307 \\
\hline$\beta_{\text {circ }} / \beta_{\text {eff }}$ & 0.529 & - & - & - & - & $0.537^{\mathrm{a}}$ & 0.435 \\
\hline$\beta_{\text {circ }}(\mathrm{pcm})$ & 181.25 & - & - & - & - & $179.5^{\mathrm{a}}$ & 133.64 \\
\hline
\end{tabular}

${ }^{a}$ Values calculated with a simplified correction method and not with ERANOS.

factor is about 0.5 with different evaluation methods. This corresponds to the proportion of the fuel salt volume in the core.

Some more precise evaluations have been performed by POLIMI with JEFF-3.1, as detailed in reference [23]. Figure 5 shows the influence of the different methods and models used to estimate the loss of the delayed neutrons due to the circulation of the fuel. We can observe that the flow distribution, for example with or without the recirculation of the fluid near the blanket wall, influences the factor calculation by up to $10-15 \%$. The recirculation trends to increase the fraction of delayed neutrons emitted in the core.

\subsubsection{Generation time}

The results are presented in Table 15 . The definitions used by each partner for the determination of the generation time are the following:

ERANOS: weighted with adjoint flux

- POLIMI SERPENT and LPSC: implicit prompt lifetime

- POLIMI SERPENT: weighted with adjoint flux (based on the Iterated Fission Probability method)

- TU Delft: lifetime evaluated as 

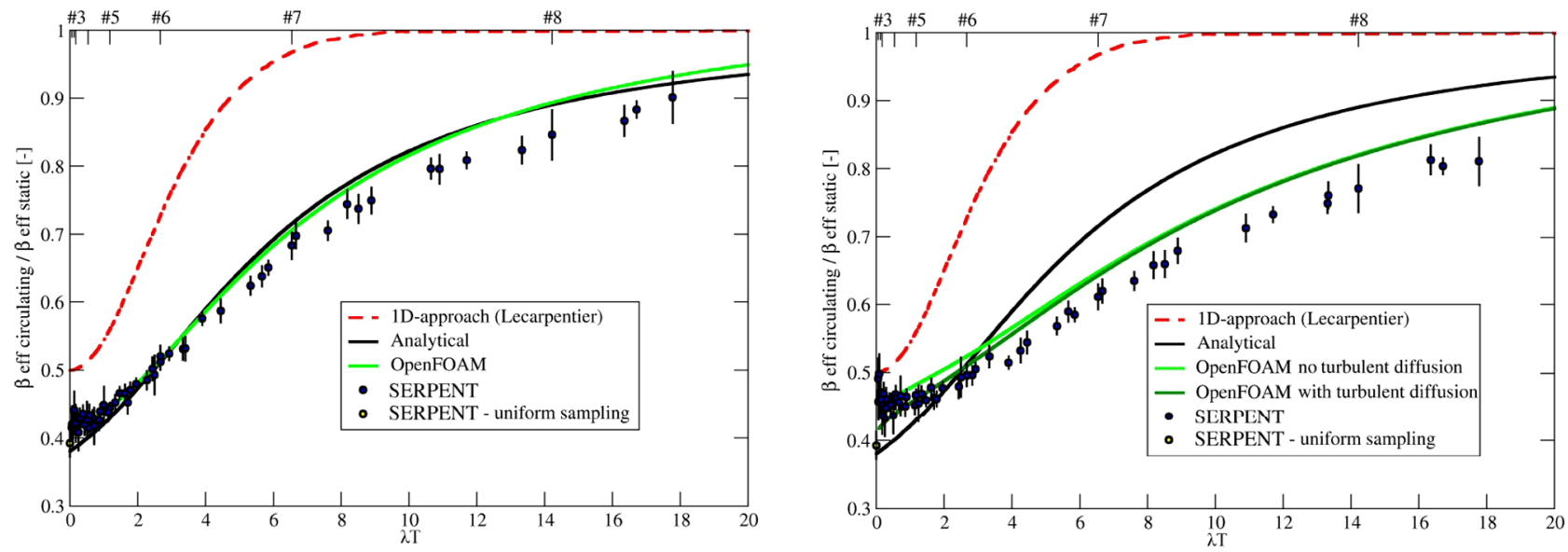

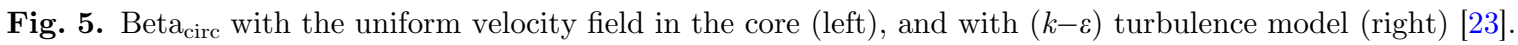

Table 15. Neutron generation time evaluation.

\begin{tabular}{|c|c|c|c|c|c|c|c|}
\hline$\mu \mathrm{s}$ & LPSC & $\begin{array}{l}\text { POLITO } \\
\text { SERPENT } \\
\text { analog }\end{array}$ & $\begin{array}{l}\text { POLITO } \\
\text { SERPENT } \\
\text { implicit }\end{array}$ & $\begin{array}{l}\text { POLIMI ERANOS } \\
\text { (adjoint- } \\
\text { weighted } \\
\text { gen. time) }\end{array}$ & $\begin{array}{l}\text { POLIN } \\
\text { (implicit } \\
\text { prompt } \\
\text { lifetime) }\end{array}$ & $\begin{array}{l}\text { SERPENT } \\
\text { (adjoint- } \\
\text { weighted gen. } \\
\text { time) }\end{array}$ & TU Delft \\
\hline$\overline{{ }^{233} \mathrm{U} \text {-started MSFR }}$ & 1.2 & 0.9694 & 0.9706 & 1.13 & 1.204 & 1.09 & 1.15 \\
\hline TRU-started MSFR & 0.9 & 0.7816 & 0.7827 & 0.64 & 0.93 & 0.65 & - \\
\hline Steady State & 1.2 & - & - & 0.96 & 0.90 & - & 1.04 \\
\hline
\end{tabular}

$$
\Lambda=\left(\frac{\overline{1}}{v}\right) \frac{1}{\overline{v \Sigma_{f}}}=\frac{\int \frac{1}{v} \phi d^{3} r d E}{\int \phi d^{3} r d E} \frac{\int \phi d^{3} r d E}{\int \nu \Sigma_{f} \phi d^{3} r d E}
$$

- POLITO analog: average time between neutron emission and absorption (cannot account for leaked neutrons)

- POLITO implicit: computed according to the following formula

$$
t_{\text {gen }}=\frac{k_{\text {eff }}}{\bar{v} \nu \Sigma_{f}} .
$$

According to different definitions used by the partners, there is a global agreement regarding the prompt lifetime calculation. POLIMI's evaluations with SERPENT are in a very good agreement with the results of LPSC using MCNP and of TU Delft, especially for the initial compositions. Adjoint-weighted generation times were calculated by POLIMI with ERANOS and SERPENT codes; for the TRU-started composition, the generation time is much lower, almost half compared to the ${ }^{233} \mathrm{U}$-started composition.

Calculations performed by POLITO using an analog and an implicit method are in a very good agreement with each other, but these values are slightly lower (around 20\%) compared to the other evaluations. This may come from the evaluation here of the "prompt neutron reproduction time," which differs from both the generation time and the average prompt lifetime of other partners.

\subsubsection{Thermal feedback coefficients}

In the benchmark, the idea was to calculate the two contributions of the feedback coefficient (Doppler and density coefficients), together with the total value and its uncertainty. LPSC calculations were performed with a $\Delta T$ of $100 \mathrm{~K}$ (neutronic calculations at $925 \mathrm{~K}$ and $1025 \mathrm{~K}$ ). Similarly, Kurchatov Institute's calculations were performed at 900 and $1000 \mathrm{~K}$. The results from POLITO were calculated at 900 and $1200 \mathrm{~K}$ (data libraries available by default in SERPENT). At POLIMI, the evaluations were carried out using three different databases: ENDF/B-6.8, ENDF/B-7 and JEFF-3.1. The Doppler coefficient was estimated by a comparison of two Monte Carlo runs with fuel temperature at 900 and $1200 \mathrm{~K}$. The density coefficient was calculated reducing the fuel density by $5 \%$ (from nominal value). The results are presented in Tables 16-20.

For TU Delft, the total feedback coefficient is calculated using the steady-state flow and setting the entire reactor first at $650^{\circ} \mathrm{C}$ and then at $750^{\circ} \mathrm{C}$. The total feedback coefficient is calculated by taking the difference between the two corresponding reactivity values and dividing by 100. As for other partners, the Doppler feedback coefficient is calculated by holding the density constant when calculating the cross sections. The density feedback coefficient is calculated while only varying the density.

The results are summarized in Figures 6 and 7 and show an overall good agreement for all compositions in the case of the initial composition of the fuel salt. The density coefficient (corresponding to the void coefficient) 
Table 16. Thermal feedback coefficient evaluated by $\mathrm{KI}$ in $\mathrm{pcm} / \mathrm{K}$.

\begin{tabular}{llllr}
\hline KI $($ ENDF-B6) & Density & Doppler & Uncertainty & Total \\
\hline${ }^{233}$ U-started MSFR & -2.8 & -4.7 & $+/-0.2 \mathrm{pcm} / \mathrm{K}$ & -7.5 \\
TRU-started MSFR & -2.7 & -1.6 & $+/-0.2 \mathrm{pcm} / \mathrm{K}$ & -4.3 \\
Steady state & -2.5 & -3.4 & $+/-0.2 \mathrm{pcm} / \mathrm{K}$ & -5.9 \\
\hline
\end{tabular}

Table 17. Thermal feedback coefficient evaluated by LPSC in $\mathrm{pcm} / \mathrm{K}$.

\begin{tabular}{llll}
\hline LPSC (ENDF-B6) & Density & Doppler & Total \\
\hline${ }^{233}$ U-started MSFR & -3.6 & -2.6 & $-6.3+/-0.1 \mathrm{pcm} / \mathrm{K}$ \\
TRU-started MSFR & -2.2 & -1.5 & $-3.8+/-0.1 \mathrm{pcm} / \mathrm{K}$ \\
Steady state & -3.2 & -2.2 & $-5.4+/-0.3 \mathrm{pcm} / \mathrm{K}$ \\
\hline
\end{tabular}

Table 18. Thermal feedback coefficient evaluated with SERPENT by POLIMI in pcm/K.

\begin{tabular}{lllllll}
\hline POLIMI & \multicolumn{3}{c}{ TRU-started } & \multicolumn{3}{c}{${ }^{233}$ U-started } \\
\hline & ENDF-B7 & ENDF-B6 & JEFF 3.1 & ENDF-B7 & ENDF-B6 & JEFF 3.1 \\
\hline Doppler & $-1.63 \pm 0.06$ & $-1.78 \pm 0.06$ & $-1.64 \pm 0.06$ & $-3.73 \pm 0.07$ & $-3.77 \pm 0.06$ & $-3.84 \pm 0.07$ \\
Density & $-2.75 \pm 0.06$ & $-2.78 \pm 0.06$ & $-2.92 \pm 0.06$ & $-3.55 \pm 0.07$ & $-3.20 \pm 0.07$ & $-3.45 \pm 0.07$ \\
\hline
\end{tabular}

Table 19. Thermal feedback coefficient evaluated by POLITO in $\mathrm{pcm} / \mathrm{K}$.

\begin{tabular}{llll}
\hline POLITO (JEFF-31) & Density & Doppler & Total \\
\hline${ }^{233}$ U-started & Analog: & Analog: & Analog: \\
& $-3.42 \pm 0.048$ & $-3.15 \pm 0.048$ & $-6.52 \pm 0.057$ \\
& Implicit: & Implicit: & Implicit: \\
& $-3.41 \pm 0.018$ & $-3.13 \pm 0.018$ & $-6.53 \pm 0.022$ \\
TRU-started & Analog: & Analog: & Analog: \\
& $-2.85 \pm 0.041$ & $-1.29 \pm 0.040$ & $-4.11 \pm 0.066$ \\
& Implicit: & Implicit: & Implicit: \\
& $-2.82 \pm 0.013$ & $-1.31 \pm 0.013$ & $-4.15 \pm 0.022$ \\
\hline
\end{tabular}

Table 20. Thermal feedback coefficient evaluated by TU Delft in $\mathrm{pcm} / \mathrm{K}$.

\begin{tabular}{llll}
\hline TU Delft & Density/void & Doppler & Total \\
\hline${ }^{233}$ U-started & -2.58 & -4.39 & -6.97 \\
Steady state $(100 \mathrm{yr})$ & & & -5.27 \\
\hline
\end{tabular}

evaluations during reactor evolution, especially for the initial transuranic composition, are in a very good agreement for different codes and different databases. For the ${ }^{233} \mathrm{U}$-started MSFR as its initial composition, the choice of the database has an influence on the density coefficient but has a negligible impact for the Doppler coefficient calculation. The evaluations of the Doppler effect for the initial transuranic composition are consistent within different codes and different nuclear data sets used. Only two calculations were available for the steady-state composition comparison. Those show some differences for the Doppler and density coefficient calculations, while keeping the total feedback coefficient consistent. Also, the evolution of the feedback coefficient evaluated by LPSC and KI shows the same tendencies, especially for the ${ }^{233} \mathrm{U}$-started MSFR.

As expected, it is to point out that the initial transuranic composition presents the smallest negative feedback coefficient. These evaluations performed by all partners confirm that the total feedback coefficient as well as its two contributions are negative, which enhances strongly the intrinsic stability of the reactor.

\subsubsection{Neutron spectrum of the MSFR}

This fuel salt composition of the MSFR with $22.5 \mathrm{~mol} \%$ of heavy nuclei leads to a fast neutron spectrum in the core, as shown in Figure 8, where the fast neutron spectrum of the simulated reference MSFR is compared to the spectra of 


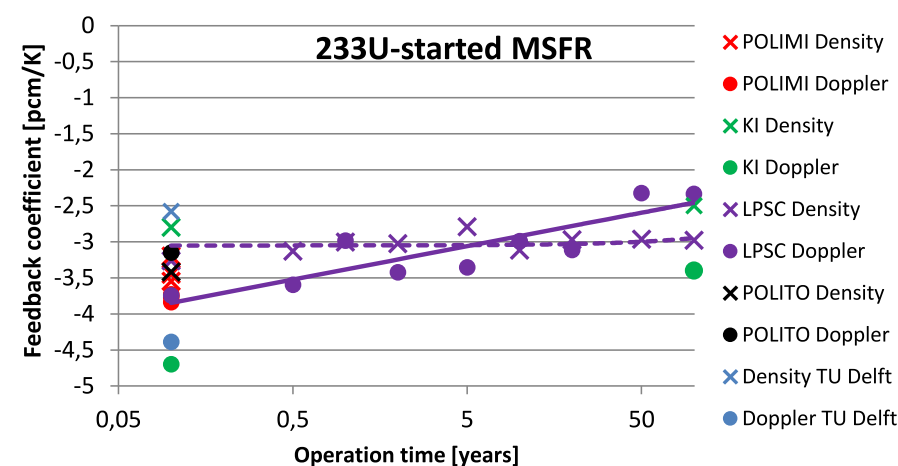

Fig. 6. Feedback coefficient evaluations for the ${ }^{233} \mathrm{U}$-started MSFR as a function of the reactor evolution time.

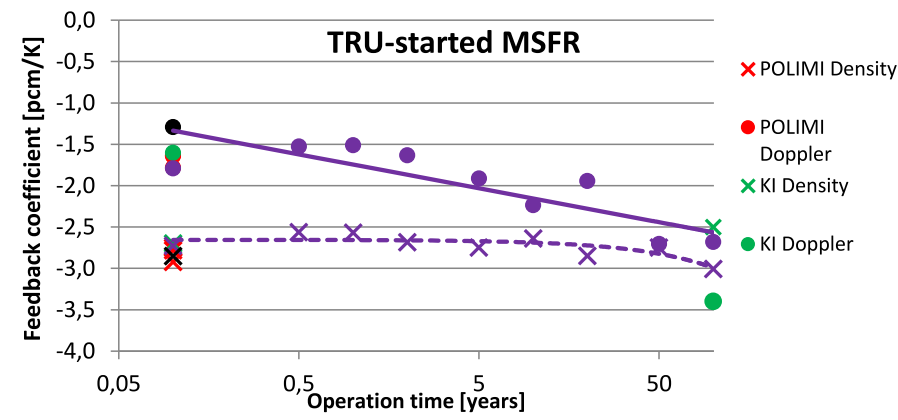

Fig. 7. Feedback coefficient evaluations for the TRU-started MSFR as a function of the reactor evolution time.

two solid-fuel reactors: a sodium-cooled fast neutron reactor (SFR) and a thermal pressurized water reactor (PWR). The large $\mathrm{Na}$ scattering cross section appears clearly on the red curve at $2.8 \mathrm{keV}$, while the scattering cross section of fluorine and lithium (see Fig. 9) shows on the green curve between 0.1 and $1 \mathrm{MeV}$.

First, the neutron spectrum calculation has been evaluated with different tools in continuous neutron energy and with the same database. The evaluations from POLITO (SERPENT), LPSC, POLIMI (SERPENT) with JEFF-3.1 are shown in Figure 10. The agreement between the curves is almost perfect. Some differences may be observed at lower energy (0.0001-0.01 MeV), which are due to the use of different energy steps at POLITO compared to LPSC and POLIMI. Some differences may also be observed around $0.1 \mathrm{MeV}$, which are due to the different options of reconstruction methods in the unresolved resonance region used for the cross section calculations. Finally, the calculations performed at KIAE with ENDF/B-6 fit perfectly with LPSC's and POLIMI's calculations despite the different databases used.

Figure 11 presents the sensitivity study of the neutron spectrum to the data basis used. Some large differences are observed using JEFF-3.1, ENDF/B-6.8 and JENDL-3 databases. These differences may be partly explained when studying the fluoride diffusion cross section (see Fig. 12). This cross section is evaluated differently within the databases JENDL-3, JEFF-3.1 or ENDF/B-6.8.

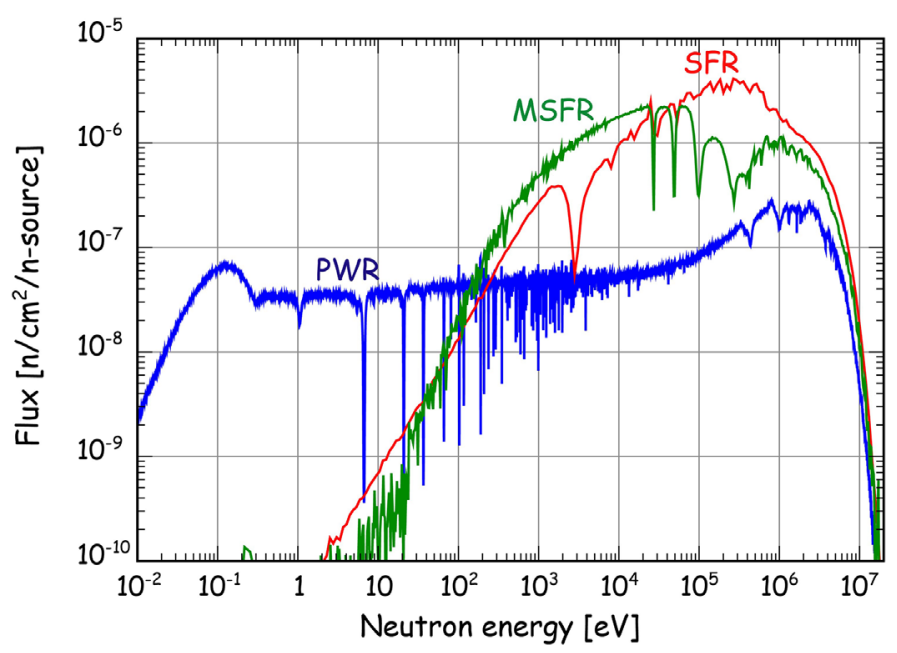

Fig. 8. Fast neutron spectra of the reference MSFR (green curve) and of a Na-cooled fast neutron reactor (FNR-Na - red curve) compared to the thermalized spectrum of a pressurized water reactor (PWR - blue curve).

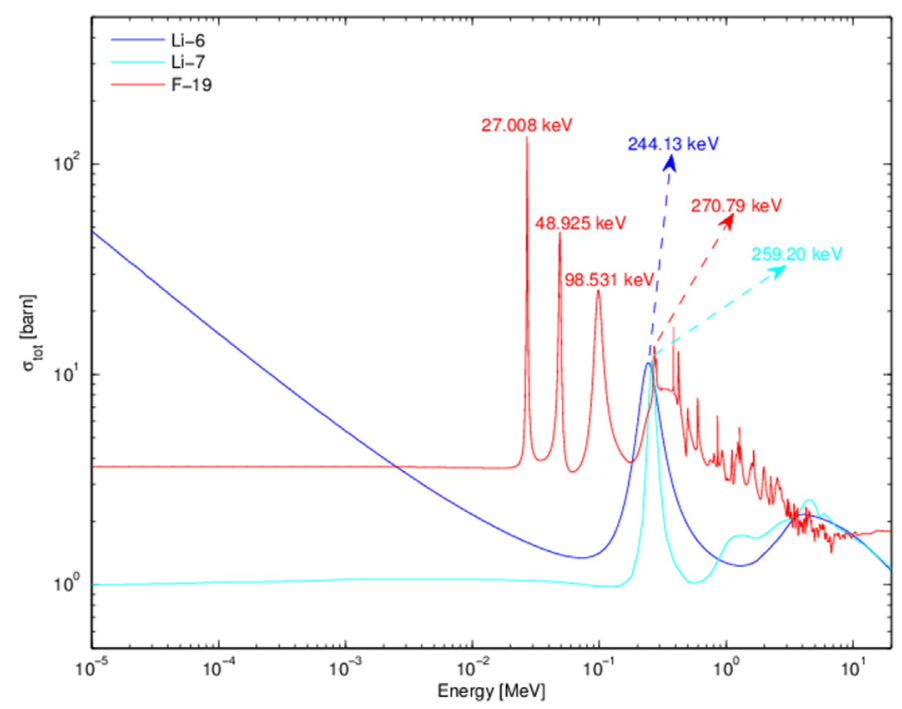

Fig. 9. Total neutron cross section of ${ }^{19} \mathrm{~F},{ }^{7} \mathrm{Li}$ and ${ }^{6} \mathrm{Li}$.

The MSFR neutron spectra calculated in the deterministic codes ERANOS (POLIMI), HELIOS (HZDR) and DALTON (TU Delft) are shown in Figure 13. The evaluated spectra show an overall good agreement. The evaluation with ERANOS presents a neutron increase at low energy $\left(10^{-8}-10^{-6} \mathrm{MeV}\right)$, which is probably due to the choice of the numerical tolerance in the calculation, since the flux value is very low in this region. The calculation performed with HELIOS presents a more significant thermal neutron contribution compared to other codes. Indeed, the volume for the flux calculation included not only the fuel salt in the core but also in the reflectors, which contributes significantly to the thermal neutron flux. 


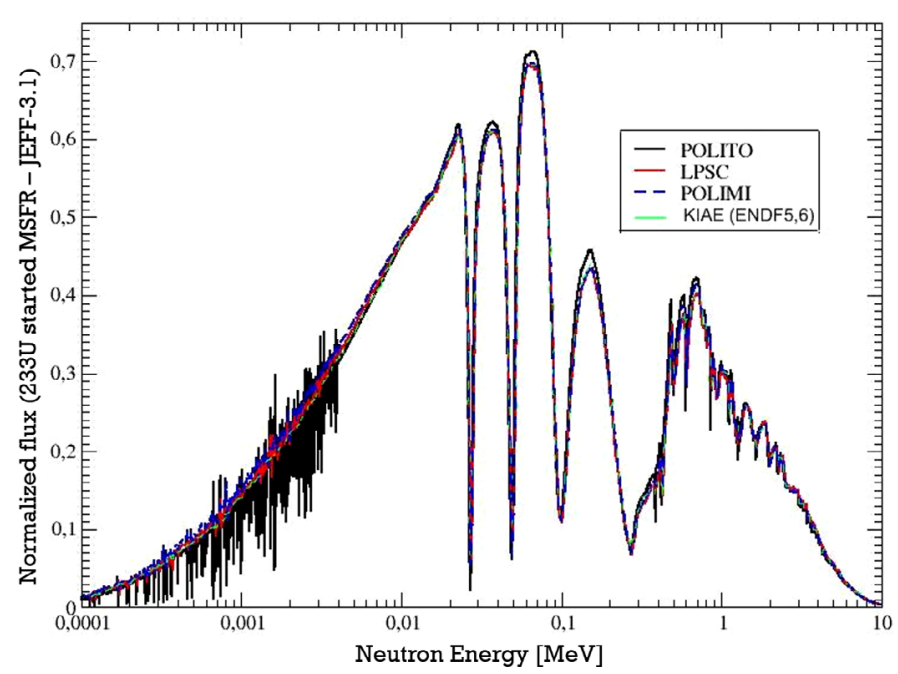

Fig. 10. Neutronic normalized flux comparison of tools performing with continuous neutron energy spectrum.

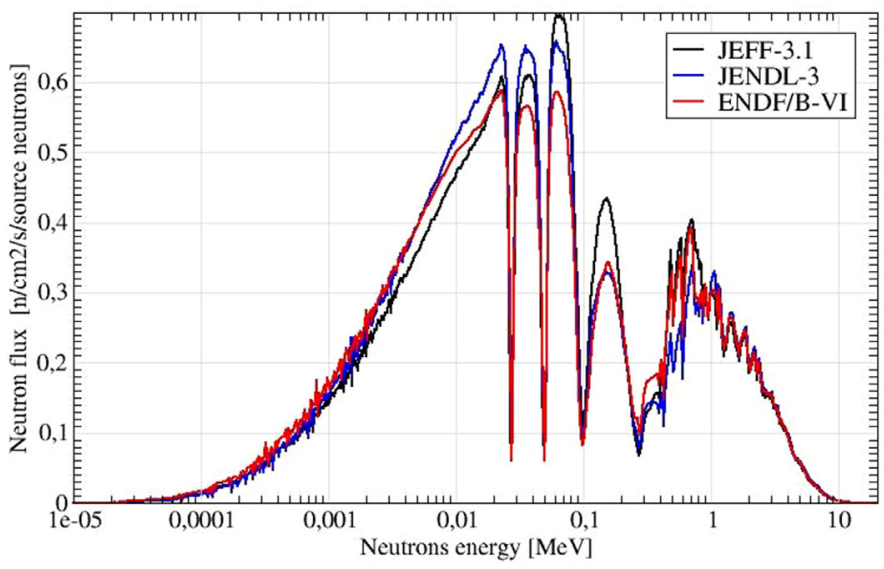

Fig. 11. Neutron flux comparison using different databases: JEFF-3.1, ENDF/B-6.8 and JENDL-3 evaluated with SERPENT (POLIMI) and MCNP (LPSC).

The neutron flux distribution in the core and the fertile blanket is represented in Figure 14. Due to the homogeneity of fuel composition, the typical cosine/Bessel shape is obtained for the flux distribution in the core. The neutron flux in the fertile blanket is one order of magnitude lower than in the core. The neutron flux in the fertile blanket is also affected by the fuel salt circulating out of the core, as shown in Figure 14.

The neutron spectrum was also studied at different radial positions to identify some spatial effects. As shown in Figure 15, the neutron spectrum is very similar for different radial positions, but it becomes slightly more thermal next to the reflector. This effect is observed for both the initial compositions.

Finally, the neutron spectrum was calculated for the different compositions of the MSFR: ${ }^{233} \mathrm{U}$-started, TRU-started MSFR initial composition and steady-state composition, as presented in Figure 16. The TRU-started composition has the fastest spectrum and the ${ }^{233} \mathrm{U}$-started

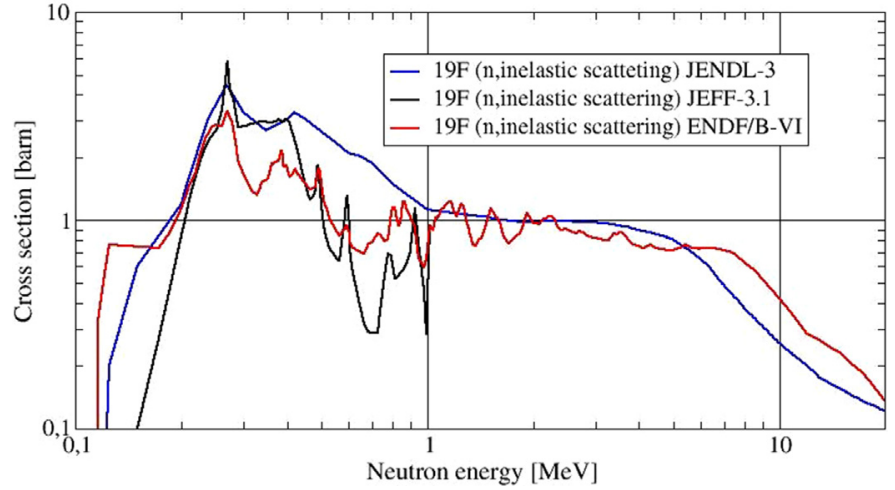

Fig. 12. Inelastic scattering neutron cross section of ${ }^{19} \mathrm{~F}$ from the databases JEFF-3.1, ENDF/B-6.8 and JENDL-3.

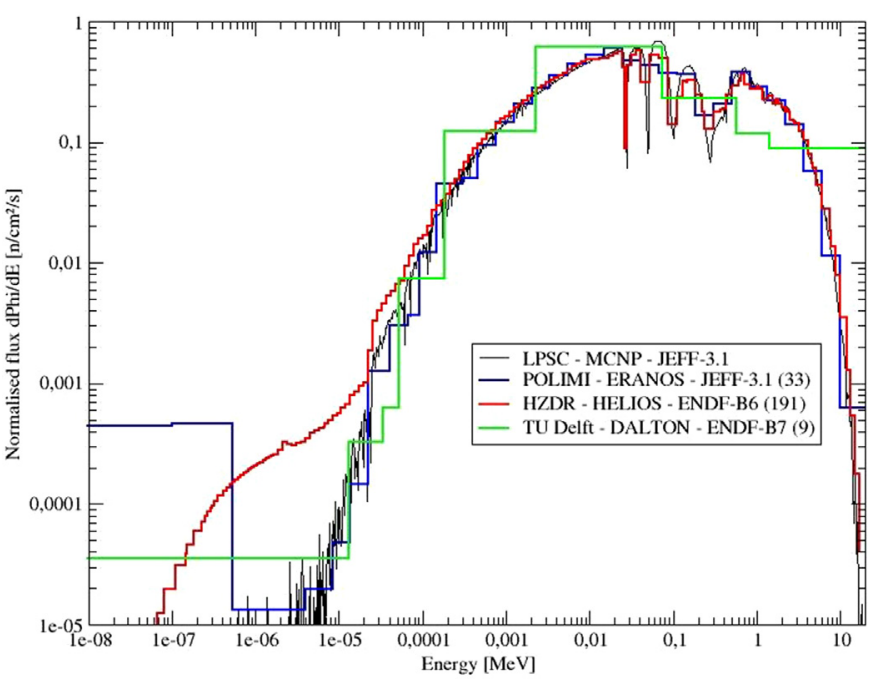

Fig. 13. Neutron flux comparison of tools performing with discrete neutron energy spectrum.

composition the most thermal one, but all three curves are very close. The impact of the fuel salt composition is quite small.

\subsection{Evolution calculations}

4.2.1 Steady-state composition and evolution of the heavy nuclei inventories

The utilization of TRU elements to start the reactor increases the initial amounts of minor actinides compared to the ${ }^{233} \mathrm{U}$-started MSFR. But at steady state, the fuel salt compositions of TRU-started and ${ }^{233} \mathrm{U}$-started MSFRs are identical, the initial TRU being converted into ${ }^{233} \mathrm{U}$, as shown in Figure 17.

$\mathrm{Th}, \mathrm{Pa}$ and $\mathrm{U}$ reach their equilibrium concentration rather quickly, while a few dozen years are necessary to burn $90 \%$ of the $\mathrm{Pu}$ and $\mathrm{Np}$ initial load and around a century for the $\mathrm{Am}$ and $\mathrm{Cm}$ elements. The in-core $\mathrm{Cm}$ inventory reaches a maximum of $390 \mathrm{~kg}$ (with $265 \mathrm{~kg}$ of ${ }^{244} \mathrm{Cm}$ ) after 26 yr of operation. 

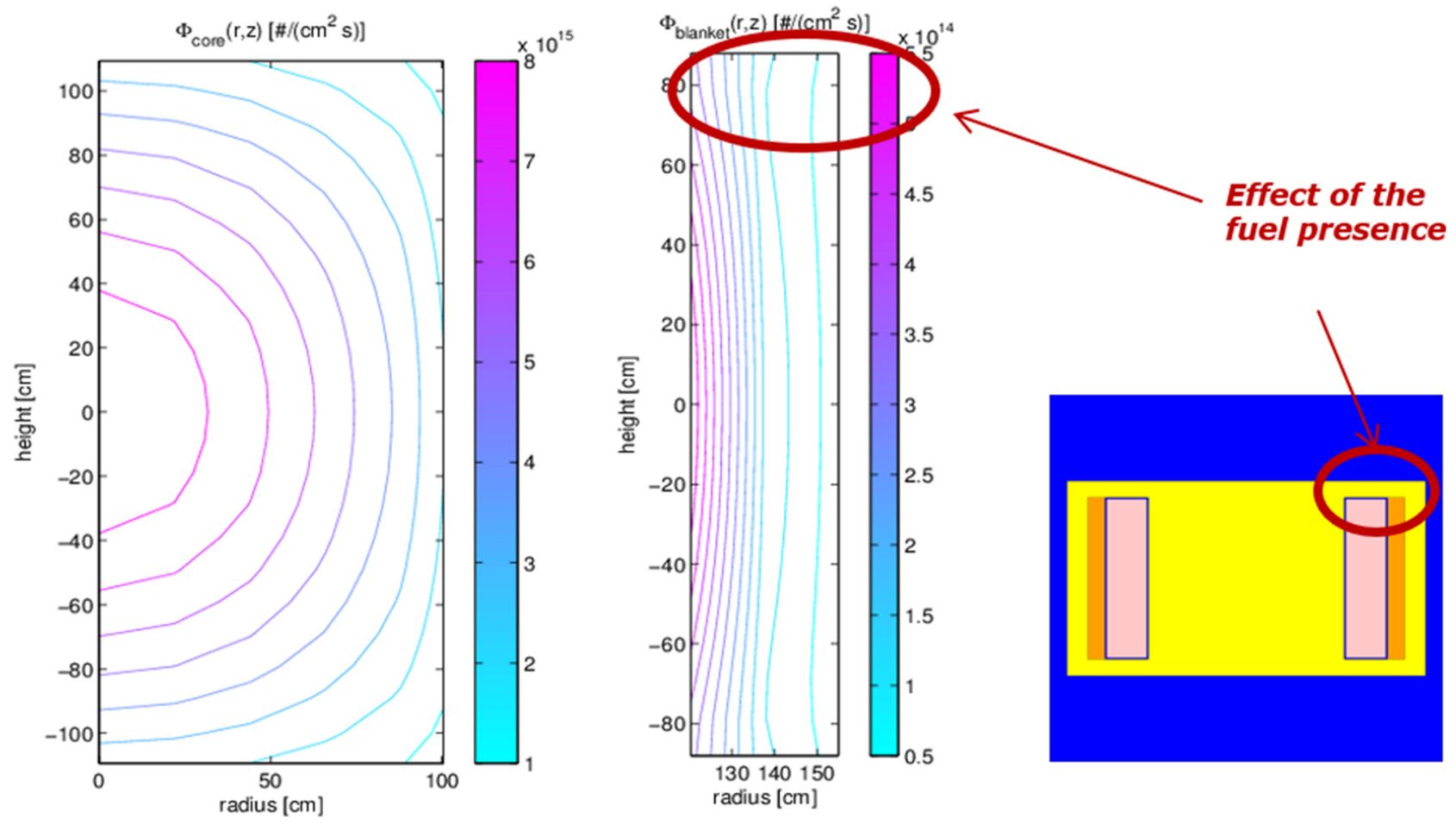

Fig. 14. Neutron flux distribution in the core and the fertile blanket (evaluated with SERPENT, POLITO).
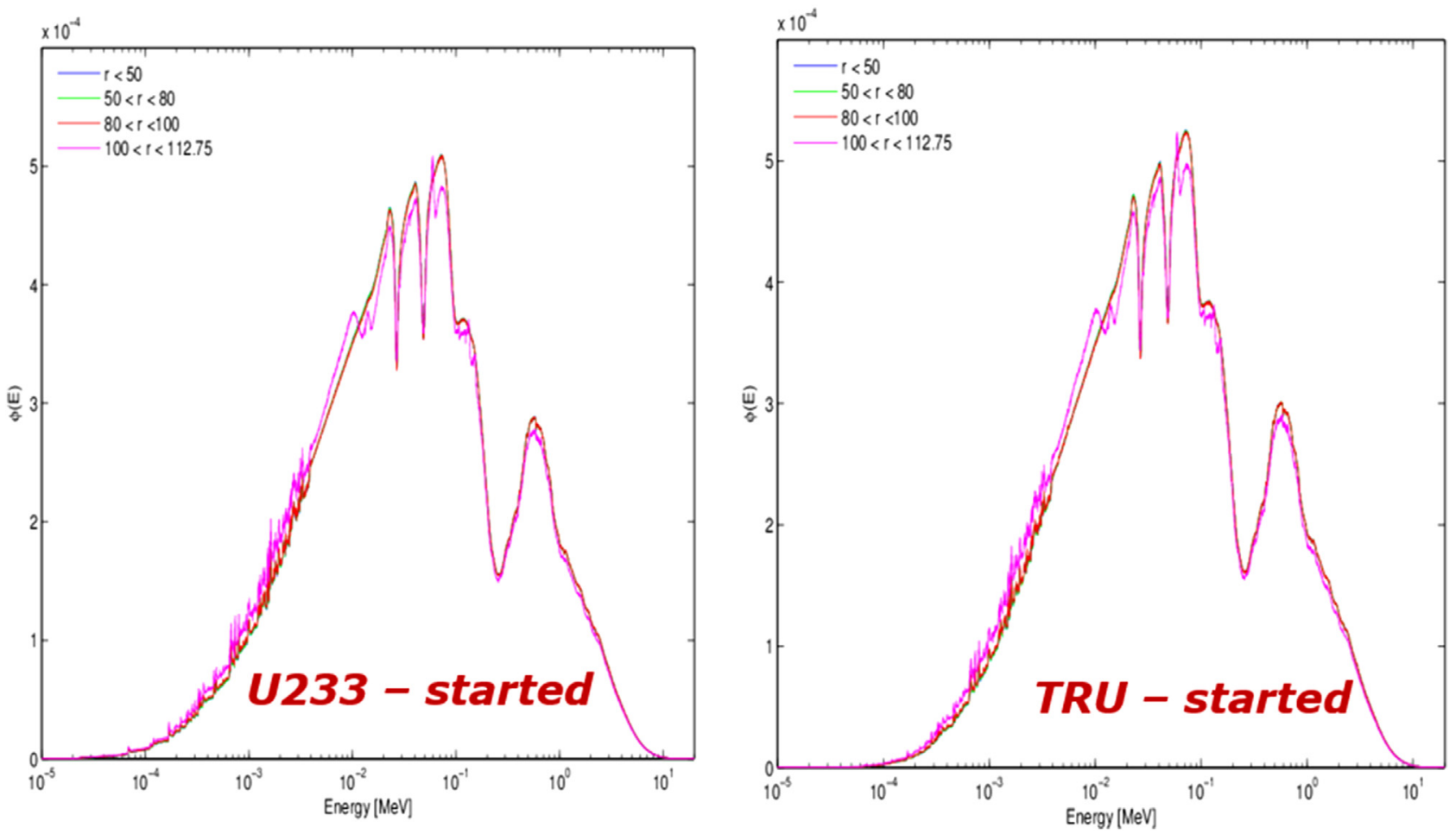

Fig. 15. Neutron spectrum comparison for different radial positions (performed with SERPENT, POLITO). 


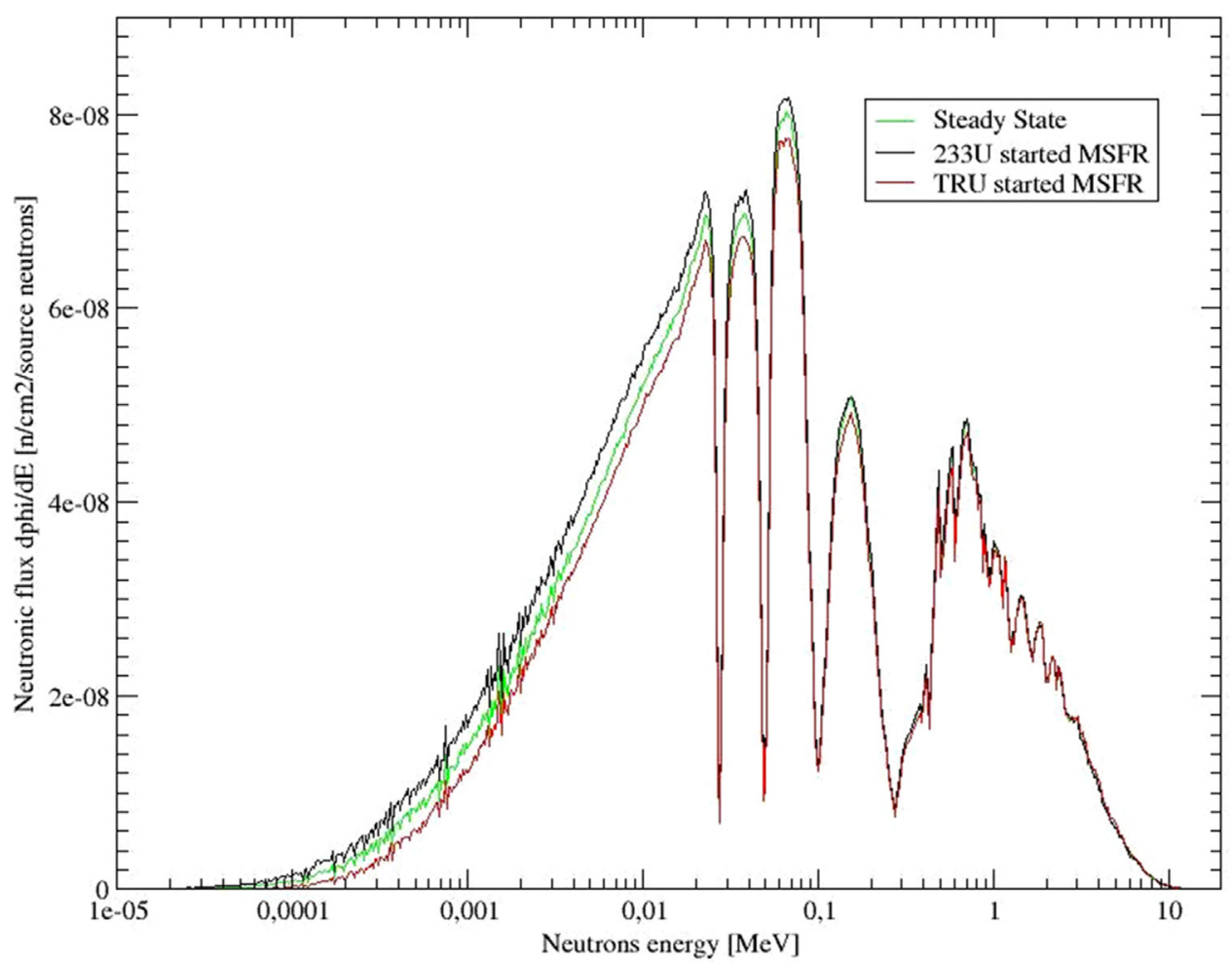

Fig. 16. Neutron spectrum comparison for different compositions (performed with MCNP, LPSC).

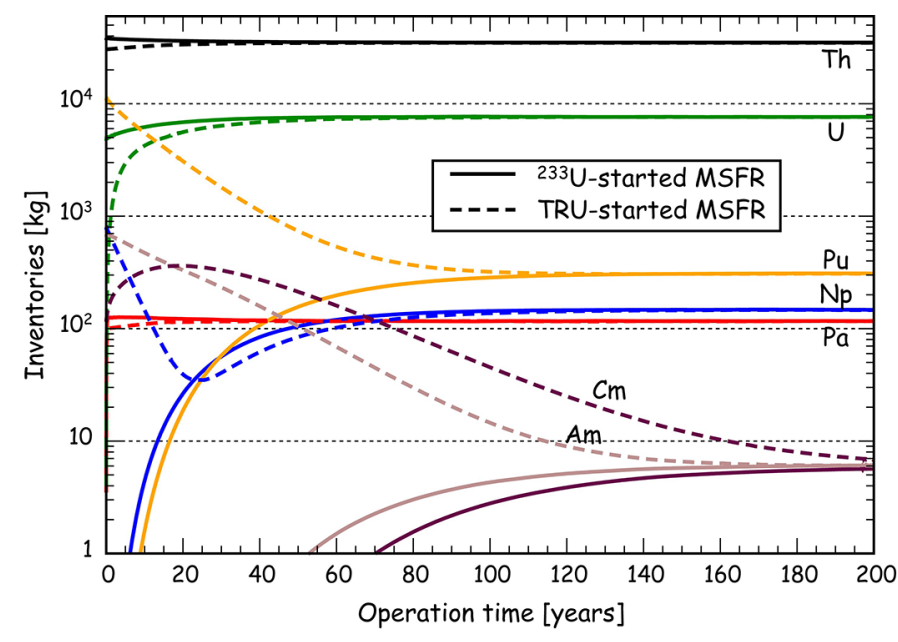

Fig. 17. Time evolution up to equilibrium of the heavy nuclei inventory for the ${ }^{233} \mathrm{U}$-started MSFR (solid lines) and for the TRU-started MSFR (dashed lines) - LPSC calculations.

As observed in Figures 18 and 20, the results obtained with different tools but with the same nuclear data sets are in very good agreement for the actinides and fission products, both for the ${ }^{233} \mathrm{U}$-started and TRU-started MSFRs. The choice of the database has an important impact on the inventories evolution (see Figs. 19 and 21). Detailed studies of the evolution of some specific nuclei are presented in the following sections.

\subsubsection{Fuel salt evolution for the ${ }^{233} \mathrm{U}$-started MSFR}

First, the evolution calculations were performed for the ${ }^{233}$ U-started MSFR. Figure 22 shows the ${ }^{233} \mathrm{U}$ and the total uranium inventory evaluated with different data sets: ENDF/B-6, ENDF/B-7 and JEFF-3.1. The uranium amount seems to be dependent on the database used. The ENDF/B-7 database shows the most important difference on the uranium inventory that is higher than with other databases. This difference may be partly explained by looking at the neutron capture cross section of ${ }^{233} \mathrm{U}$, evaluated in different databases, as shown in Figure 4. Indeed, in the range of $0.001-0.1 \mathrm{MeV}$, the cross sections are evaluated differently, and ENDF/B-7 evaluation seems to be the highest one regarding the neutron capture.

Since the data basis seems to have an impact on the uranium inventory in the fuel salt, the tool comparison was performed while using the same data basis. Figures 23-25 show the tool comparison used by LPSC, POLIMI (ERANOS and SERPENT), TU Delft and KI. One can observe that the uranium and ${ }^{233} \mathrm{U}$ inventories are in a very good agreement, especially for longer operation time. ${ }^{233} \mathrm{U}$ inventory evaluated with the deterministic code ERANOS is however slightly lower compared to the evaluation with the other tools.

${ }^{232} \mathrm{U}$ and ${ }^{231} \mathrm{~Pa}$ isotopes inventories were also compared as presented in Figure 26, evaluated using the ENDF/B-6 and ENDF/B-7 databases. The evaluations of ${ }^{232} \mathrm{U}$ inventory are in good agreement. The stockpile of ${ }^{231} \mathrm{~Pa}$ 


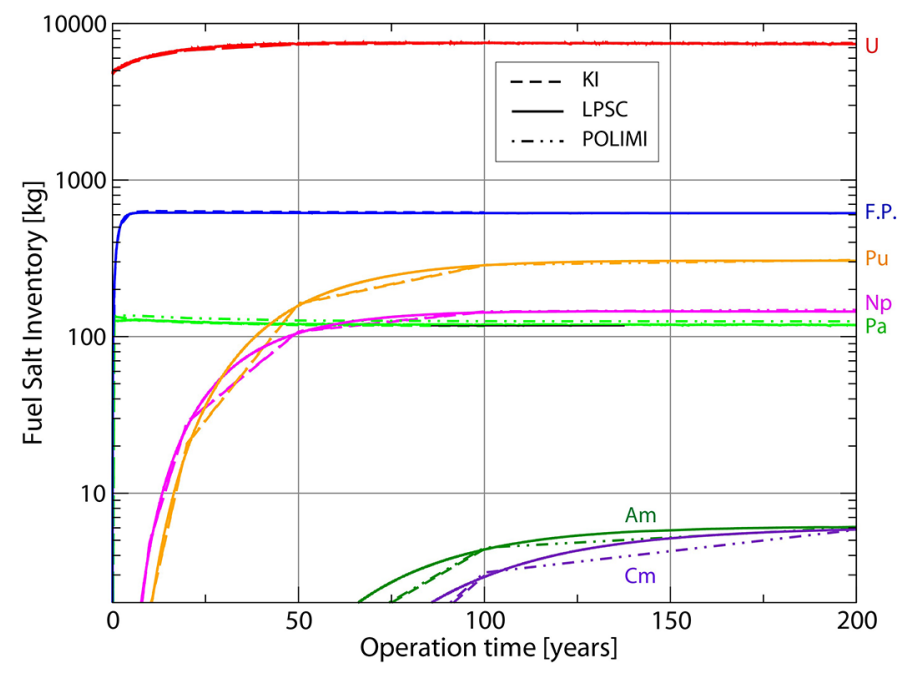

Fig. 18. Time evolution of the trans-Th elements and fission products for the ${ }^{233} \mathrm{U}$-started MSFR evaluated by different tools with the same database ENDF/B-6.

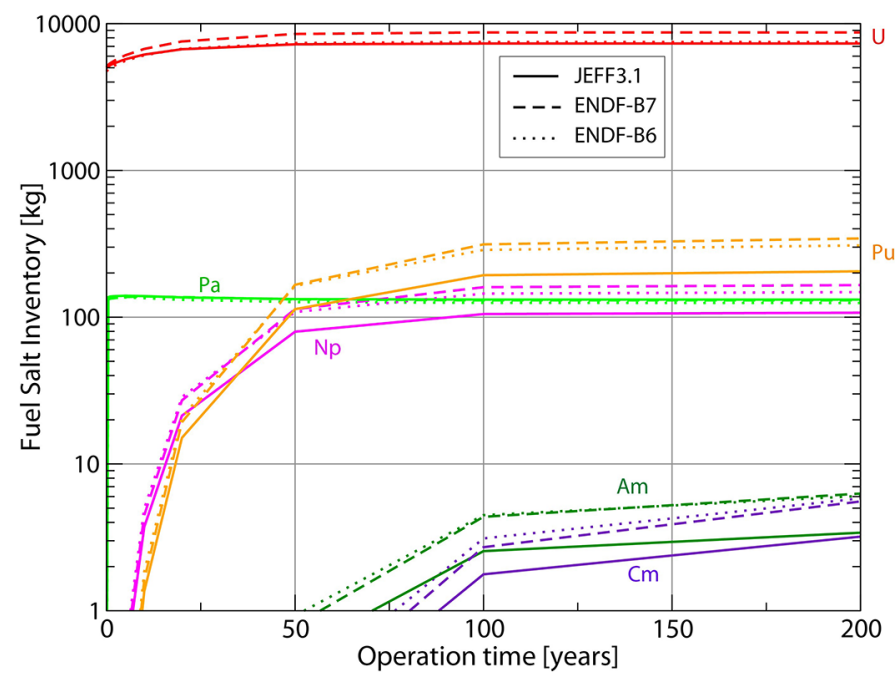

Fig. 19. Time evolution of the trans-Th elements for the ${ }^{233} \mathrm{U}$-started MSFR evaluated by POLIMI (SERPENT tool) with the different databases.

evaluated at Kurchatov Institute is lower compared to those calculated at LPSC and POLIMI (SERPENT). Similarly, with the ENDF/B-7 database, the evaluations of POLIMI (SERPENT) are lower than that of TU Delft.

The inventories of different plutonium isotopes calculated with SERPENT (POLIMI) with different databases are presented in Figure 27. Similar to uranium isotopes, the choice of the database has influence only on the plutonium isotopes inventories. Different simulations performed by the partners with the same database (ENDF-B6) are thereby in a very good agreement as shown in Figure 28.

\subsubsection{Fuel salt evolution for the TRU-started MSFR}

For the TRU-started MSFR simulations, the evolution of the minor actinides inventory in the core has been

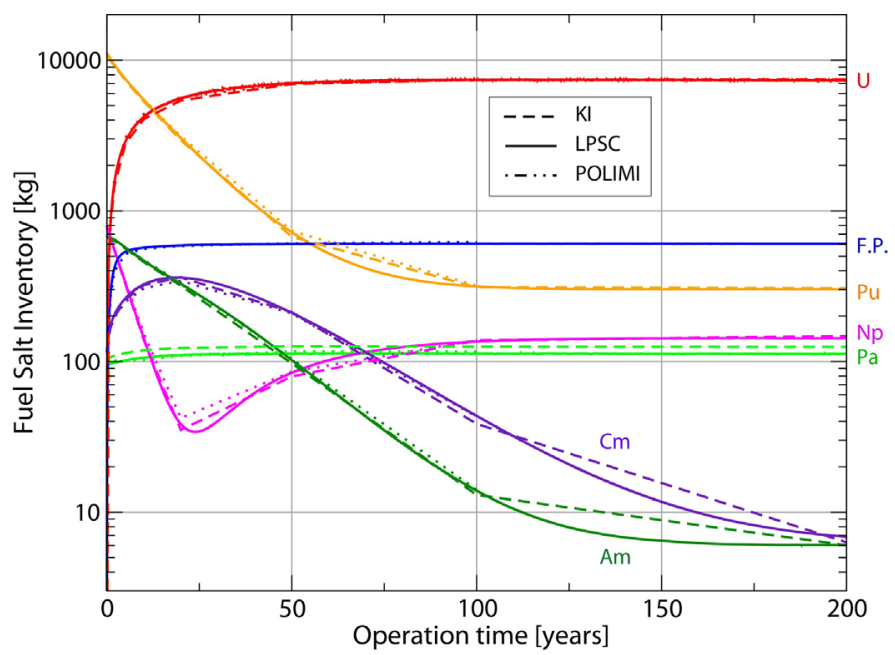

Fig. 20. Time evolution of the trans-Th elements and fission products for the TRU-started MSFR evaluated by different tools with the same database ENDF/B-6.

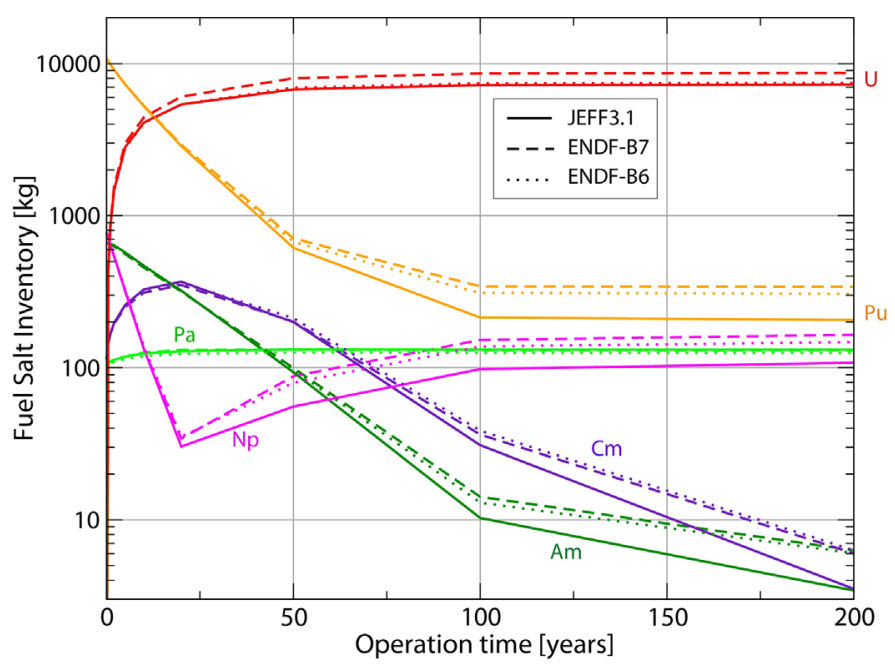

Fig. 21. Time evolution of the trans-Th elements for the TRU-started MSFR evaluated by POLIMI (SERPENT tool) with the different databases.

calculated and is presented in Figure 29. This transuranic elements inventory considered here included the $\mathrm{Pu}, \mathrm{Np}$, $\mathrm{Am}$ and $\mathrm{Cm}$ elements. This inventory is reduced from 12 tons to some hundreds of kilograms at steady state. The different simulations show a very good agreement on this minor actinides burning. When considering the plutonium inventory, as shown in Figure 30, similar conclusions are found.

During TRU-started MSFR operation, the uranium quantity increases as presented in Figure 31. As observed previously, the database used for the calculation has only a small impact on the uranium inventory of the fuel salt. Thereby, the ${ }^{233} \mathrm{U}$ inventory is in a very good agreement for different databases, see Figure 32. 


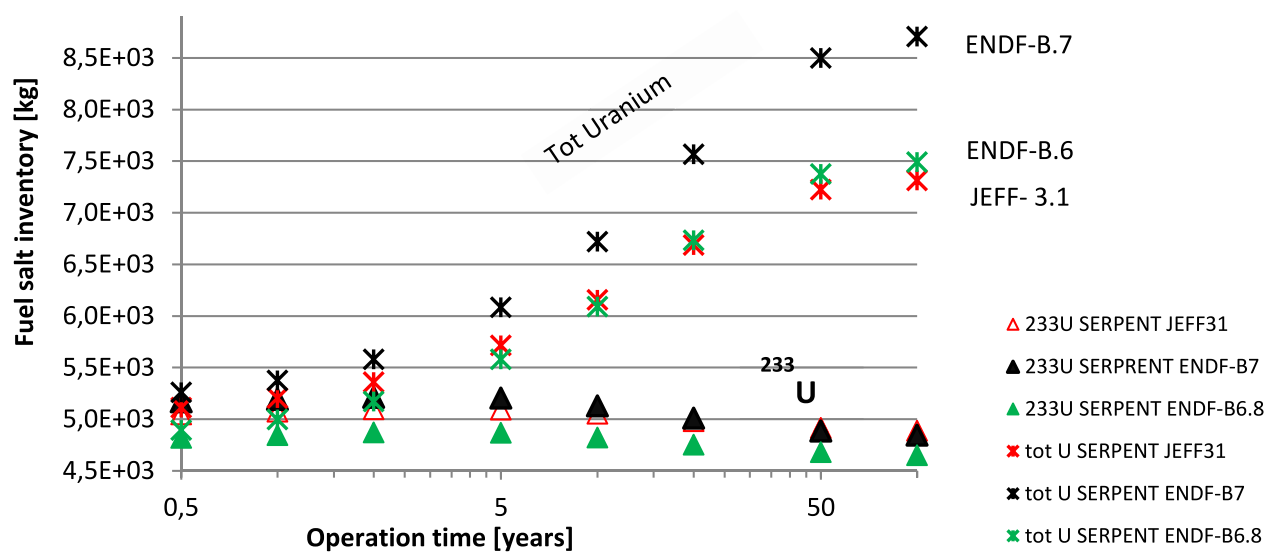

Fig. 22. Fuel salt inventory in uranium and ${ }^{233} \mathrm{U}$ with ENDF/B-6, ENDF/B-7 and JEFF-3.1 databases (performed with SERPENT, POLIMI).

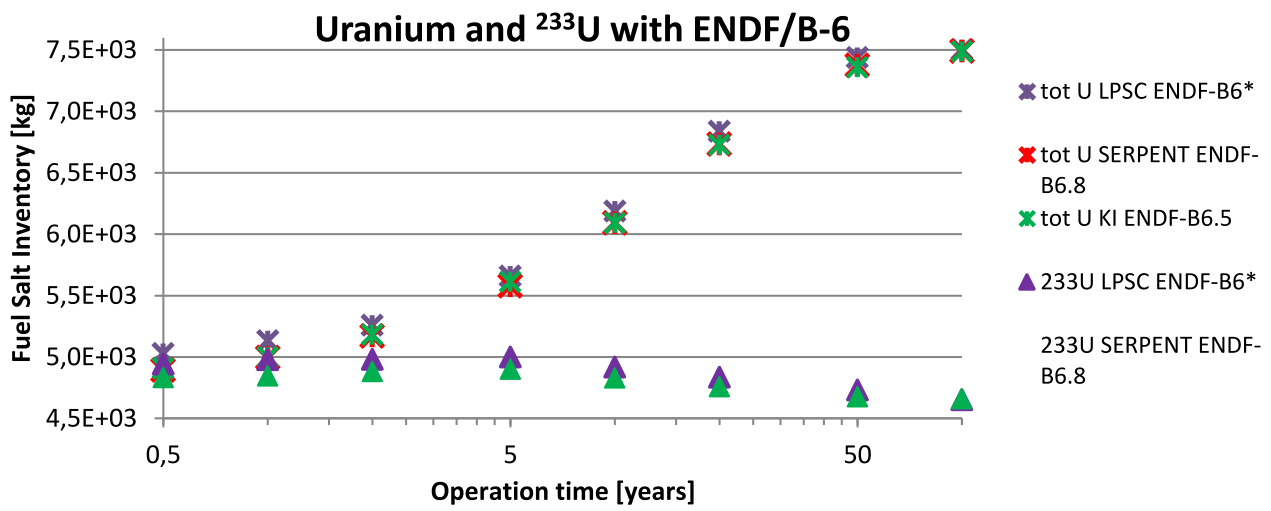

Fig. 23. Fuel salt inventory in uranium and ${ }^{233} \mathrm{U}$ with ENDF/B-6 data basis performed by POLIMI (SERPENT), LPSC and KI.

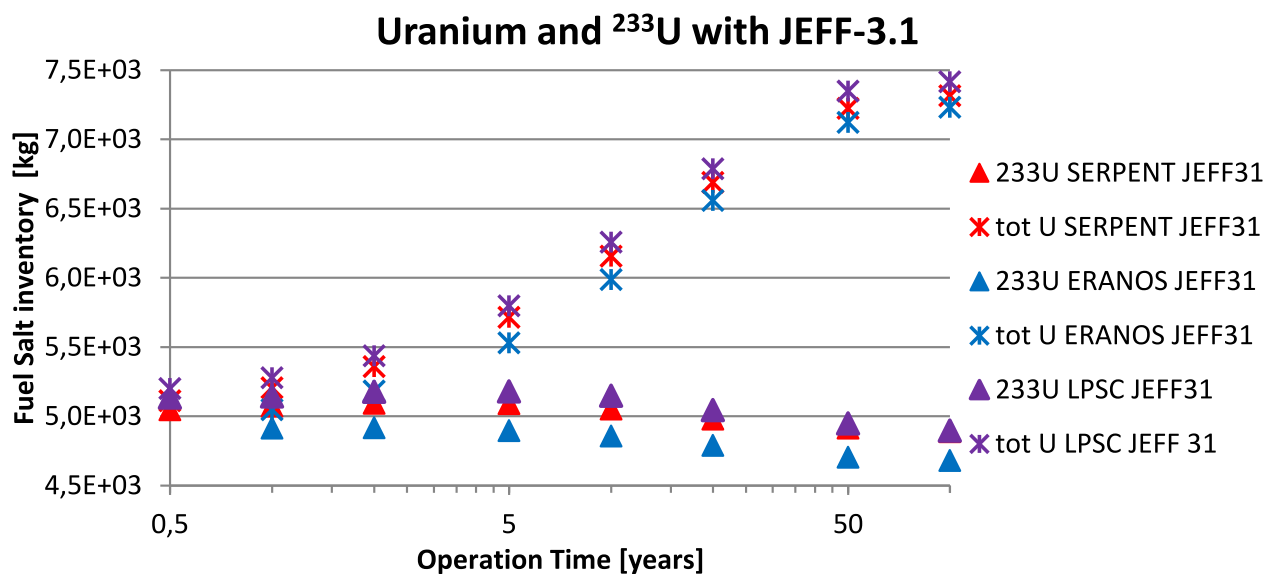

Fig. 24. Fuel salt inventory in uranium and ${ }^{233} \mathrm{U}$ with JEFF-3.1 data basis performed by POLIMI (SERPENT), POLIMI (ERANOS) and LPSC.

\subsubsection{Evolution of the fission products composition}

In order to compare the fission products extraction simulated in the various evolution codes, the total fission products inventory as a function of the operation time was calculated as shown in Figure 33. The values obtained at TU Delft, LPSC and Kurchatov Institute are in a very good agreement, while the ERANOS calculation leads to a fission products inventory reduced by a factor 2. This difference is due to the assumptions used in the ERANOS code evolution, where some fission products are neglected in the inventory.

\subsubsection{Breeding gain and breeding ratio evolution}

The breeding gain was defined in the benchmark template as a ratio of uranium in the core and the blanket, so that the uranium extracted from the blanket, and uranium supply 


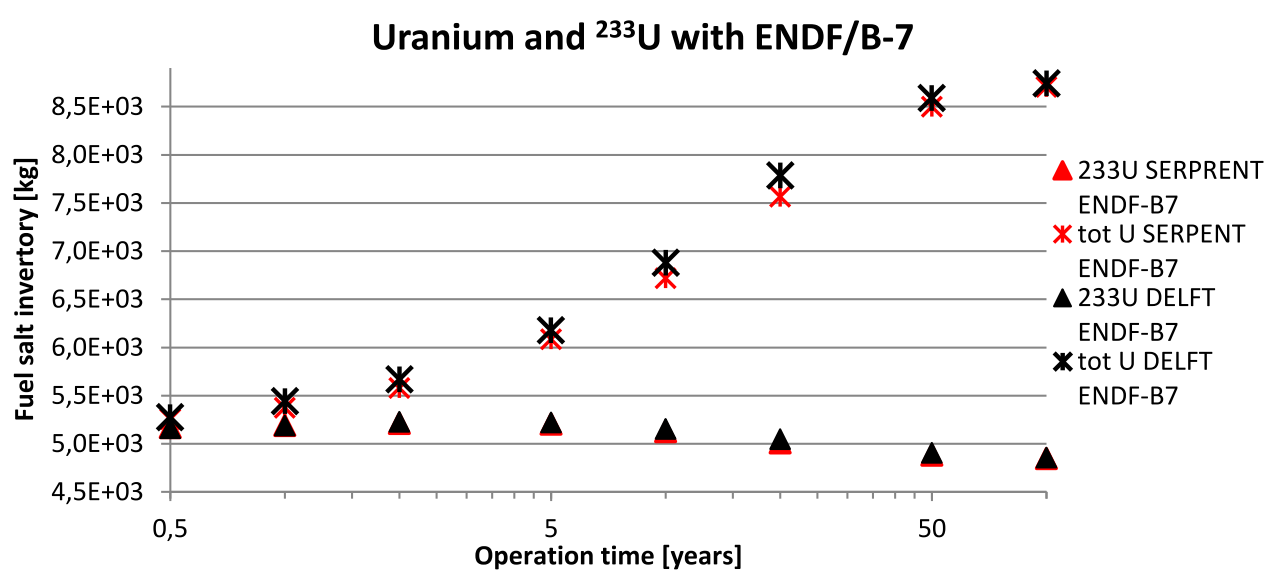

Fig. 25. Fuel salt inventory in uranium and ${ }^{233} \mathrm{U}$ with ENDF/B-7 database performed by POLIMI (SERPENT), TU Delft.



Fig. 26. Fuel salt inventory in ${ }^{232} \mathrm{U}$ and ${ }^{231} \mathrm{~Pa}$.

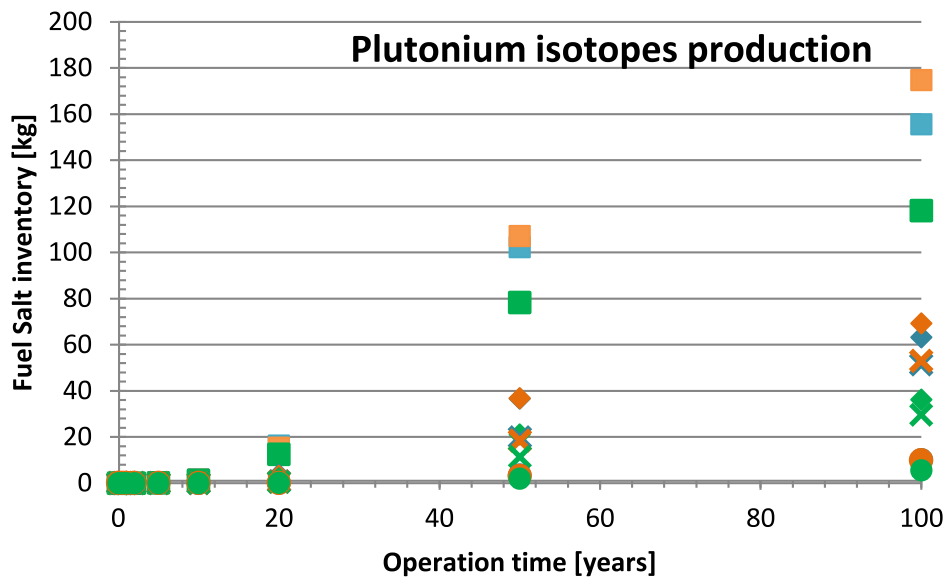

238PU SERPENT ENDF-B6 238PU SERPENT ENDF-B7 238PU SERPENT JEFF31

$\checkmark 239$ PU SERPENT ENDF B6

239PU SERPENT ENDF-B7

$\checkmark 239$ PU SERPENT JEFF31

$\times 240$ PU SERPENT ENDF-B6 $\times 240$ PU SERPENT ENDF-B7 $\times 240$ PU SERPENT JEFF31

- 241PU SERPENT ENDF-B6

241PU SERPENT ENDF-B7

- 241PU SERPENT JEFF31

Fig. 27. Evolution of the plutonium isotopes in the fuel salt according to POLIMI (SERPENT).

in the core, has to be taken into account.

$$
\begin{aligned}
B G & =\frac{\text { Extra produced fissile material }}{\text { Operation time }} \\
& \left.=\text { Balance of }{ }^{233} \mathrm{U} \text { (system: core }+ \text { blanket }\right)
\end{aligned}
$$

The calculations of the breeding gain for the ${ }^{233}$ U-started MSFR are presented in Figure 34. The values calculated by the different partners with the same database (ENDF/B-6) are very close, around $90 \mathrm{~kg} / \mathrm{yr}$. While changing the database, this value can be increased up to $140 \mathrm{~kg} / \mathrm{yr}$ (JEFF-3.1) or decreased down to $50 \mathrm{~kg} / \mathrm{yr}$ 
Plutonium isotopes production

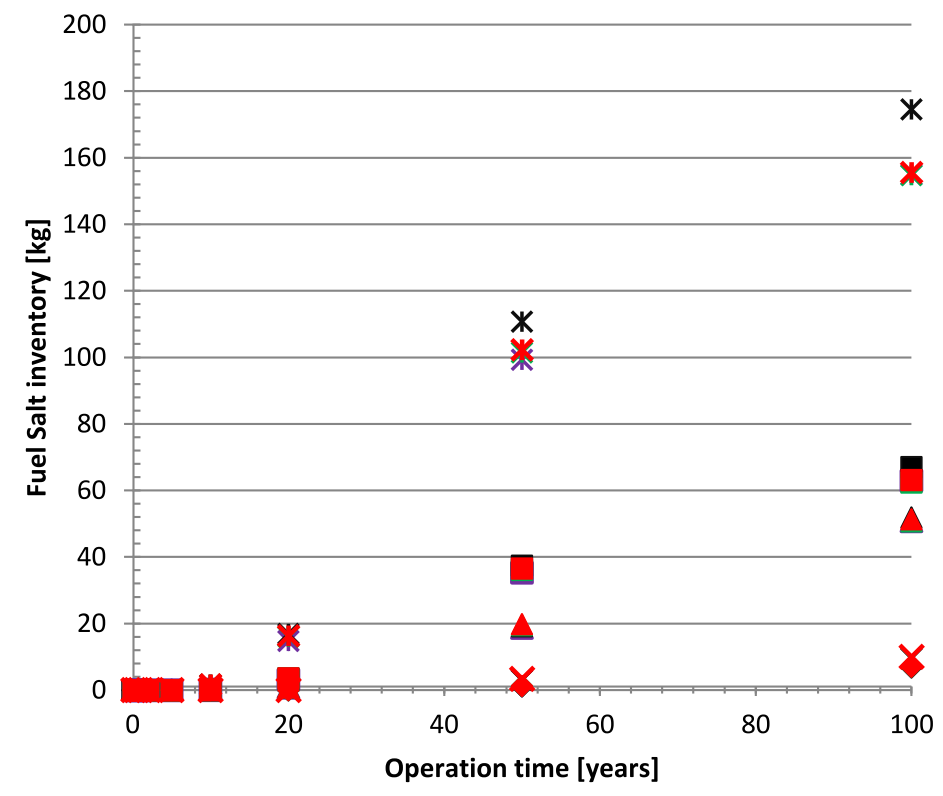

-242PU LPSC ENDF-B6

$\times 241$ Pu LPSC ENDF-B6

$\triangle 240$ PU LPSC ENDF-B6

239Pu LPSC ENDF-B6

* 238Pu LPSC ENDF-B6

- 242Pu TU Delft ENDF-B7

$\times 241 P u$ TU Delft ENDF-B7

$\triangle 240 P u$ TU Delft ENDF-B7

- 239Pu TU Delft ENDF-B7

※238Pu TU Delft ENDF-B7

-242Pu ENDF-B6

$\times 241$ Pu ENDF-B6

$\triangle 240$ Pu KI ENDF-B6

239PU KI ENDF-B6

※ 238PU KI ENDF-B6

× 238PU SERPENT ENDF-B6

- 239PU SERPENT ENDF B6

$\triangle 240$ PU SERPENT ENDF-B6

$\times$ 241PU SERPENT ENDF-B6

- 242PU SERPENT ENDF-B6

Fig. 28. Evolution of the plutonium isotopes in the fuel salt using the ENDF-B6/7 databases.

Transuranic elements

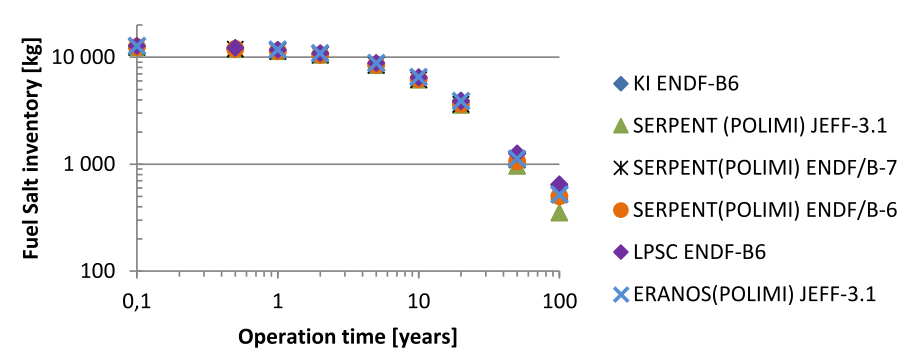

Fig. 29. Fuel salt inventory in transuranic elements during reactor evolution.

(ENDF/B-7). The ENDF-B7 database gives the lowest values, consistently with the highest evaluation of the ${ }^{233} \mathrm{U}$ capture cross section in the $0.001-0.1 \mathrm{MeV}$ energy region.

The same definition of the breeding gain was used for the TRU-started MSFR, as presented in Figure 35. The breeding gain after $100 \mathrm{yr}$ of operation is about $140 \mathrm{~kg} / \mathrm{yr}$, which is higher than the one obtained for ${ }^{233} \mathrm{U}$-started MSFR. This difference may be explained by the fact that the TRU-started MSFR is using its initial load of minor actinides to produce power, the produced ${ }^{233} \mathrm{U}$ being stored; while in the ${ }^{233} \mathrm{U}$-started MSFR, a part of the produced ${ }^{233} \mathrm{U}$ is directly fissioned. A breeding gain taking into account a balance of all the fissile matters and not only ${ }^{233} \mathrm{U}$ would be more precise in the case of the TRU-started MSFR.

Similar conclusions may be observed concerning the impact of the database used: the different codes are in a good agreement, especially at longer term when using the same database.
The breeding ratio of the MSFR, as described below, has also been evaluated:

$$
B R=\frac{\text { Decay rate of }{ }_{91}^{233} \mathrm{~Pa}}{\text { Capture + Fission rate of }{ }_{92}^{233} \mathrm{U}} .
$$

The results, listed in Table 21, are in good agreement when using the same database (see LPSC and KI calculations), except for the results provided by POLITO. Their definition of the breeding ratio is indeed different from that suggested in the template, corresponding to:

$$
\begin{aligned}
\mathrm{BR}_{\mathrm{U} 233} & =\frac{\text { Capture rate in }{ }_{90}^{232} \mathrm{Th}}{\text { Capture }+ \text { Fission rate of }{ }_{92}^{233} \mathrm{U}} \\
\mathrm{BR}_{\mathrm{TRU}} & =\frac{\text { Capture rate in }{ }_{90}^{232} \mathrm{Th}}{\text { Capture }+ \text { Fission rate in TRU }} .
\end{aligned}
$$

This last definition relying on the capture rate of the ${ }^{232} \mathrm{Th}$ and not on the decay of the produced ${ }^{233} \mathrm{~Pa}$, the delay corresponding to the period of the ${ }^{233} \mathrm{~Pa}$ is neglected, as for the possible parasitic captures on the ${ }^{233} \mathrm{~Pa}$. This leads to a light overestimation of the breeding ratio, mainly at the beginning of life of the reactor.

\section{Conclusions}

A large range of important neutronic parameters calculated by multiple benchmark participants were compared, using different calculation tools, databases and methods. An overall good agreement could be observed for the static neutronic parameters as thermal feedback coefficients, delayed neutron fractions, generation time, neutron flux 


\section{Plutonium}

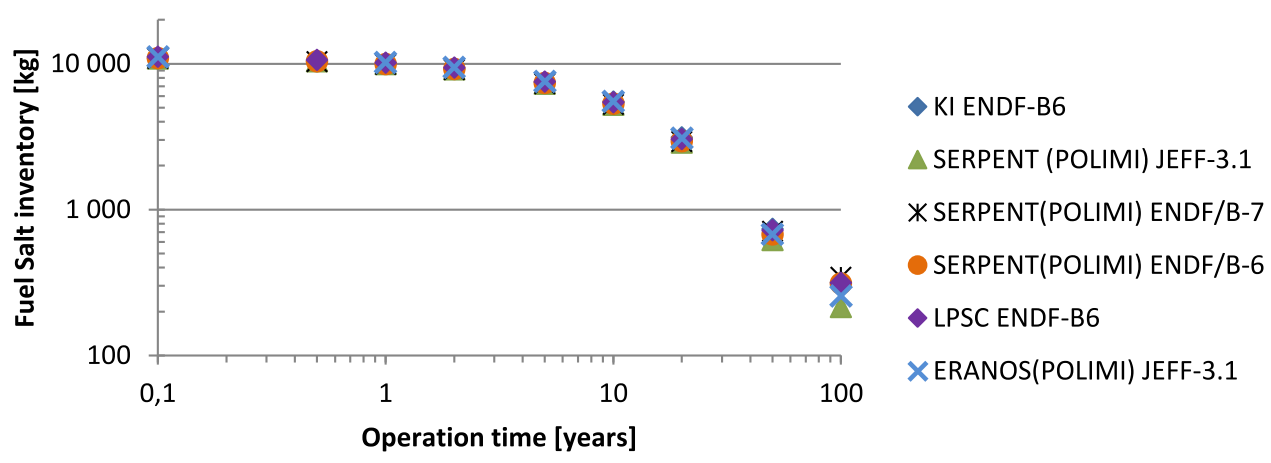

Fig. 30. Fuel salt inventory in plutonium during reactor evolution.



Fig. 31. Fuel salt inventory in uranium during reactor evolution.

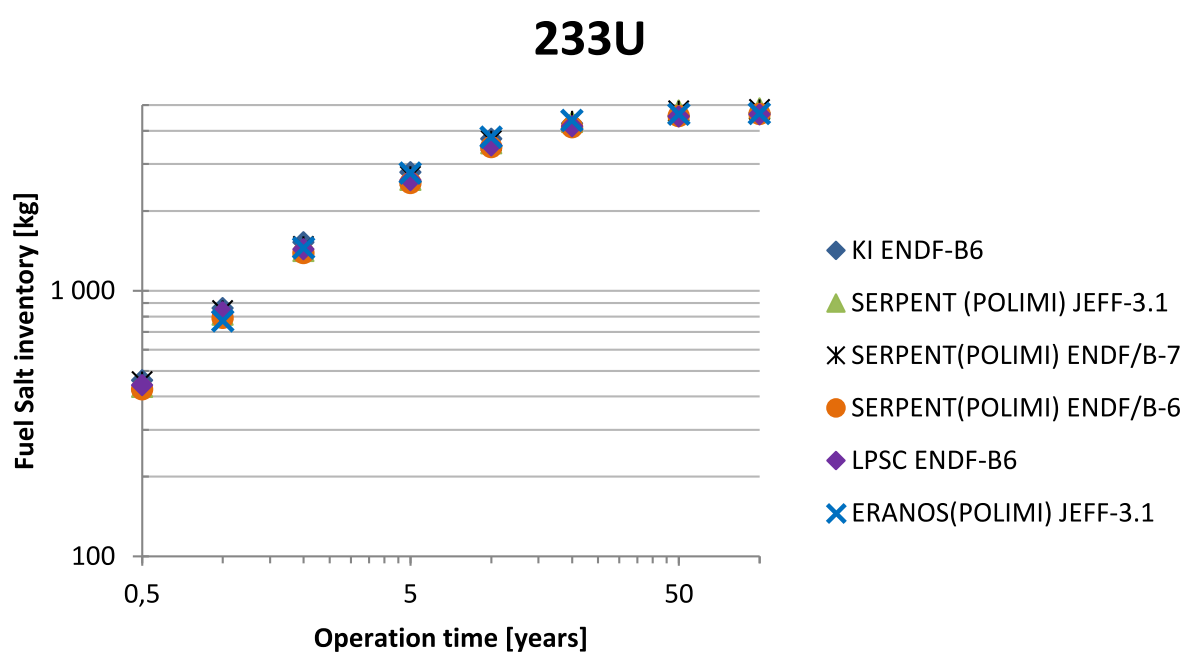

Fig. 32. Fuel salt inventory in ${ }^{233} \mathrm{U}$ during reactor evolution.

and initial critical nuclide composition. Only small discrepancies were thereby observed for the evaluations based on different calculation tools, the main one being due to hypotheses in the FP evolution calculation by ERANOS, while the choice of the nuclear database has a more consequent impact on all the results.
As mentioned above, during the initial reactor design studies, in particular those related to the neutronic calculations, the MSFR core was approximated as a single compact cylinder $(2.25 \mathrm{~m}$ high $\times 2.25 \mathrm{~m}$ diameter $)$. The next step is the thermal-hydraulics simulations benchmark. Preliminary thermal-hydraulics calculations 


\section{Fission Products}

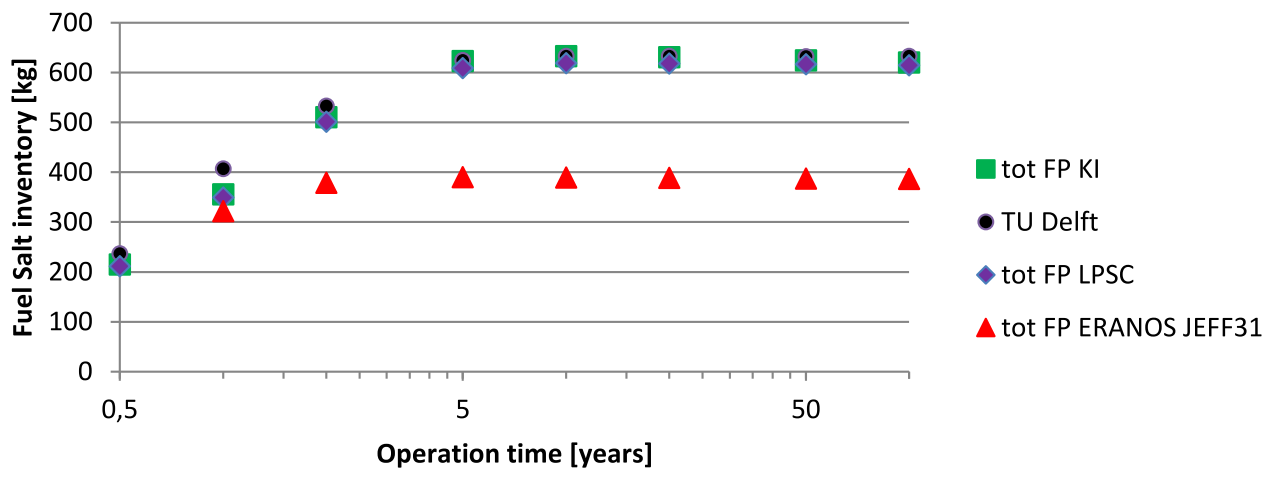

Fig. 33. Evolution of the fission products content for in the fuel salt ${ }^{233} \mathrm{U}$-started MSFR as a function of the operation time.

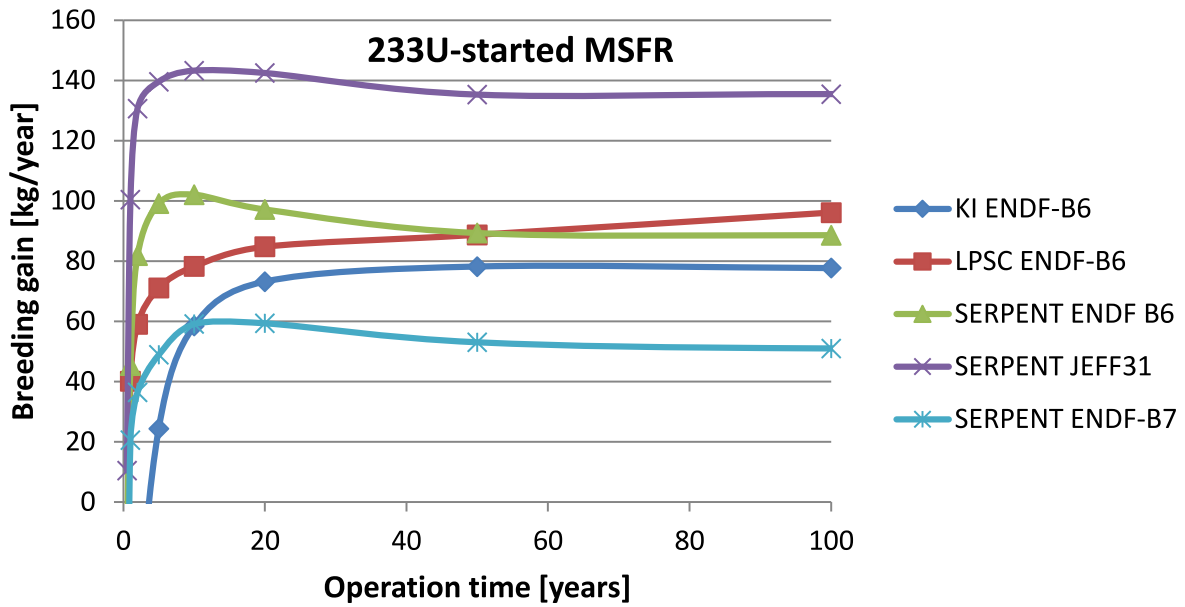

Fig. 34. Evolution of breeding gain of the ${ }^{233} \mathrm{U}$-started MSFR as a function of the operation time.

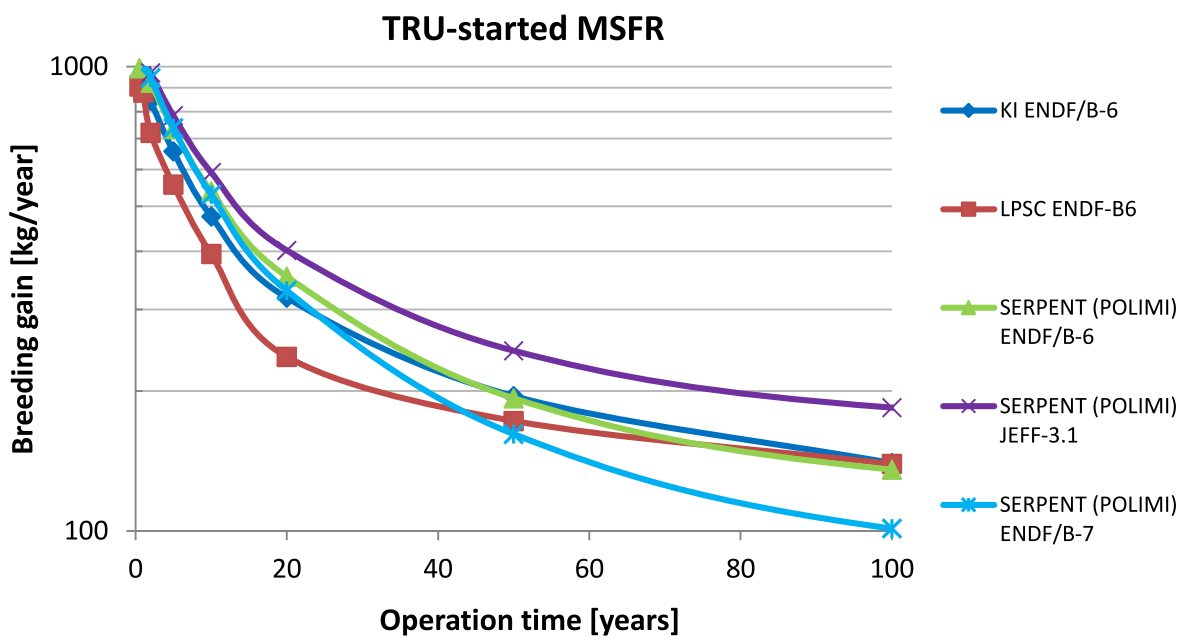

Fig. 35. Evolution of breeding gain of the TRU-started MSFR as a function of the operation time.

performed in the frame of the EVOL project have shown that the simple design used for the first benchmark of neutronic calculations induces a hot spot in the salt flow. Because it is not efficient to compare results too far from the working point of the MSFR, a more complex torus geometry has been designed for the thermal-hydraulics benchmark in order to obtain acceptable thermal-hydraulic performances [24-28]. 
Table 21. Breeding ratio evaluation with different tools and databases.

\begin{tabular}{|c|c|c|c|c|c|c|}
\hline $\mathrm{BR}$ (w/o units) & $\begin{array}{l}\text { KI (ENDF/ } \\
\text { B-6) }\end{array}$ & $\begin{array}{l}\text { LPSC } \\
(\text { ENDF/B-6) }\end{array}$ & $\begin{array}{l}\text { POLIMI } \\
\text { SERPENT } \\
\text { (JEFF-3.1) }\end{array}$ & $\begin{array}{l}\text { POLIMI } \\
\text { SERPENT } \\
(\text { ENDF/B-7) }\end{array}$ & $\begin{array}{l}\text { TU Delft } \\
\text { (core only) }\end{array}$ & $\begin{array}{l}\text { POLITO } \\
\text { (JEFF3.1) }\end{array}$ \\
\hline Steady state $\left({ }^{233} \mathrm{U}\right.$-started $)$ & 1.07 & 1.13 & 1.112 & 1.039 & 0.944 & - \\
\hline Steady state (TRU-started) & 1.07 & 1.11 & 1.112 & 1.039 & - & - \\
\hline${ }^{233} \mathrm{U}$-started initial composition & - & $\begin{array}{l}0.664 \\
(6 \text { months })\end{array}$ & - & - & $\begin{array}{l}0.95 \\
(6 \text { months })\end{array}$ & 1.137 \\
\hline TRU-started initial composition & - & - & - & - & - & 0.610 \\
\hline
\end{tabular}

Since 2005, R\&D on molten salt reactors has been focused on fast spectrum concepts (as for the MSFR), which have been recognized as long-term alternative to solid-fuelled fast neutron systems with attractive features such as large negative temperature and void coefficients, low fissile inventory, simplified fuel cycle, waste reduction, etc. No show stoppers have been identified but almost all the technology remains to be tested and a safety approach dedicated to this type of reactors has to be developed to assess the potential advantages and to prove the viability of such innovative of fast-spectrum molten salt systems.

\section{Author contribution statement}

The neutronic benchmark of the FP7 EVOL European project involved several partners. The benchmark has been prepared and coordinated by Mariya Brovchenko and Elsa Merle from the CNRS-IN2P3-LPSC team, in charge of this task in the EVOL project. All the authors were involved in the calculations presented in the article and the corresponding presentation of the results in the article, the calculations being performed with each partner's calculation tools. The analysis of the results has been done with all the authors under the supervision of the CNRS-IN2P3-LPSC authors. Finally, the writing of the article has been coordinated by Mariya Brovchenko and Elsa Merle, with Jan-Leen Kloosterman from TU Delft, Lelio Luzzi from POLIMI and Sandra Dulla from POLITO.

\section{References}

1. H. Boussier et al., The molten salt reactor in generation IV: overview and perspectives, in Proceedings of the Generation 4 International Forum Symposium, San Diego, USA, 2012

2. M.E. Whatley et al., Engineering development of the MSBR fuel recycle, Nucl. Appl. Technol. 8, 170 (1970)

3. A. Nuttin, D. Heuer et al., Potential of thorium molten salt reactors, Prog. Nucl. Energy 46, 77 (2005)

4. L. Mathieu, D. Heuer et al., The thorium molten salt reactor: moving on from the MSBR, Prog. Nucl. Eng. 48, 664 (2006)
5. L. Mathieu, D. Heuer, E. Merle-Lucotte et al., Possible configurations for the thorium molten salt reactor and advantages of the fast non-moderated version, Nucl. Sci. Eng. 161, 78 (2009)

6. C.W. Forsberg et al., Liquid salt applications and molten salt reactors, Revue Générale du Nucléaire 4, 63 (2007)

7. E. Merle-Lucotte, D. Heuer et al., Introduction of the physics of molten salt reactor, in Materials Issues for Generation IV Systems, NATO Science for Peace and Security Series B (Springer, Berlin, 2008), pp. 501-521

8. E. Merle-Lucotte, D. Heuer et al., Minimizing the fissile inventory of the molten salt fast reactor, Proceedings of the Advances in Nuclear Fuel Management IV (ANFM 2009), Hilton Head Island, USA, 2009

9. E. Merle-Lucotte, D. Heuer et al., Optimizing the burning efficiency and the deployment capacities of the molten salt fast reactor, in Proceedings of the International Conference Global 2009-The Nuclear Fuel Cycle: Sustainable Options $\mathcal{E}$ Industrial Perspectives, Paris, France, Paper 9149, 2009

10. GIF (Generation IV International Forum), Annual Report 2008, pp. 36-41. Available at http://www.gen-4.org/PDFs/ GIF_2008_Annual Report.pdf

11. GIF (Generation IV International Forum), Annual Report 2009, pp. 52-58. Available at http://www.gen-4.org/PDFs/ GIF-2009-Annual-Report.pdf

12. GIF (Generation IV International Forum), Annual Report 2013, pp. 82-91. Available at https://www.gen-4.org/gif/ jcms/c 64097/2013-gif-annual-report

13. C. Renault et al., The molten salt reactor (MSR) in Generation IV: overview and perspectives, in Proceedings of the GIF Symposium 2009, Paris, France, 2009. Available at http://www.gen-4.org/GIF/About/documents/30-Ses sion2- 8-Renault.pdf

14. J. Serp et al., The molten salt reactor (MSR) in generation IV: overview and perspectives, Prog. Nucl. Energy 77, 308 (2014)

15. M. Allibert, M. Aufiero, M. Brovchenko, S. Delpech, V. Ghetta, D. Heuer, A. Laureau, E. Merle-Lucotte, in Handbook of Generation IV Nuclear Reactors, edited by I. Pioro, Woodhead Publishing Series in Energy (Woodhead Publishing, Duxford, UK, 2015)

16. D. Gérardin et al., Design evolutions of the molten salt fast reactor, in Proceedings of the Fast Reactors 2017 International Conference, Jekaterinburg, Russian Federation, 2017

17. V. Ignatiev, V. Afonichkin, O. Feynberg, A. Merzlyakov, A. Surenkov, V. Subbotin, et al., Molten salt reactor: new possibilities, problems and solutions, At. Energy 112, 157 (2012) 
18. S. Delpech, E. Merle-Lucotte, D. Heuer et al., Reactor physics and reprocessing scheme for innovative molten salt reactor system, J. Fluorine Chem. 130, 11 (2009)

19. M. Allibert, M. Aufiero, T. Auger, M. Brovchenko A. Cammi, S. Delpech, S. Dulla, O. Feynberg, D. Heuer, V. Ignatiev, J.L. Kloosterman, D. Lathouwers, A. Laureau, L. Luzzi, E. Merle-Lucotte, P. Ravetto, Evaluation of Irradiation Damage of Structural Materials for the MSFR, Deliverable D2.4, EVOL (Evaluation and Viability of Liquid fuel fast reactor system) European FP7 project, Contract number: 249696, 2014

20. S. Delpech, E. Merle-Lucotte, T. Augé, D. Heuer, MSFR: material issued and the effect of chemistry control, in Proceedings of the Generation IV International Forum Symposium, Paris, France, 2009

21. X. Doligez, D. Heuer, E. Merle-Lucotte et al., Numerical tools for molten salt reactors simulations, in Proceedings of the International Conference Global 2009-The Nuclear Fuel Cycle: Sustainable Options \& Industrial Perspectives, Paris, France, 2009

22. A. d'Angelo, Overview of the delayed neutron data activities and results monitored by the NEA/WPEC subgroup 6, Prog. Nucl. Energy 41, 5 (2002)

23. M. Aufiero, M. Brovchenko, A. Cammi, I. Clifford, O. Geoffroy, D. Heuer, A. Laureau, M. Losa, L. Luzzi, E. MerleLucotte, M.E. Ricotti, H. Rouch, Calculating the effective delayed neutron fraction in the molten salt fast reactor: analytical, deterministic and Monte Carlo approaches, Ann. Nucl. Energy 65, 78 (2014)

24. A. Laureau et al., Transient coupled calculations of the Molten Salt Fast Reactor using the transient fission matrix approach, Nucl. Eng. Des. 316, 112 (2017)

25. A. Laureau, Développement de modèles neutroniques pour le couplage thermohydraulique du MSFR et le calcul de paramètres cinétiques effectifs, Ph.D. thesis, Grenoble Alpes University, France (in French), 2015

26. C. Fiorina, M. Aufiero, A. Cammi, F. Franceschini, J. Krepel, L. Luzzi, K. Mikityuk, M.E. Ricotti, Investigation of the MSFR core physics and fuel cycle characteristics, Prog. Nucl. Energy 68, 153 (2013)

27. A. Laureau, P. Rubiolo, D. Heuer, E. Merle-Lucotte, M. Brovchenko, Coupled neutronics and thermal-hydraulics numerical simulations of the molten salt fast reactor (MSFR), in Joint International Conference on Supercomputing in Nuclear Applications and Monte Carlo 2013, Paris, France, October 27-31, 2013

28. H. Rouch, O. Geoffroy, P. Rubiolo, A. Laureau, B. Brovchenko, D. Heuer, E. Merle-Lucotte, Preliminary thermal-hydraulic core design of the molten salt fast reactor (MSFR), Ann. Nucl. Energy 64, 449 (2014)

29. V. Ignatiev, O. Feynberg, A. Merzlyakov et al., Progress in development of MOSART concept with Th support, in Proceedings of ICAPP 2012, Paper 12394 Chicago, USA, 2012 30. HELIOS Methods, Studsvik Scandpower, 2003

31. X. Doligez, Influence du retraitement physico-chimique du sel combustible sur le comportement du MSFR et sur le dimensionnement de son unité de retraitement, Ph.D. thesis, Grenoble Institute of Technology (Grenoble INP), France, 2010

32. A. Nuttin, Potentialités du concept de réacteur à sels fondus pour une production durable d'énergie nucléaire basée sur le cycle thorium en spectre épithermique, Ph.D. thesis,
Université Joseph Fourier - Grenoble I, France, 2002 (in French)

33. L. Mathieu, Cycle Thorium et Réacteurs à Sel Fondu: Exploration du champ des Paramètres et des Contraintes définissant le Thorium Molten Salt Reactor, Ph.D. thesis, Grenoble Institute of Technology, France, 2005 (in French)

34. E. van der Linden, Coupled neutronics and computational fluid coupled neutronics and computational fluid dynamics for the molten salt fast reactor, Master thesis, Delft University of Technology (TU Delft), 2012

35. L.L.W. Frima, Burnup in the molten salt fast reactor (MSFR), Master thesis, Delft University of Technology (TU Delft), 2013

36. C. Fiorina, A. Cammi, J. Krepel, K. Mikityuk, M.E. Ricotti, Preliminary analysis of the MSFR fuel cycle using modified-EQL3D procedure, in Proceedings of the International Conference ICONE, Anaheim, CA, 2012

37. C. Fiorina, M. Aufiero, A. Cammi, C. Guerrieri, J. Krepel, L. Luzzi, K. Mikityuk, M.E. Ricotti, Analysis of the MSFR core neutronics adopting different neutron transport models, in Proceedings of the International Conference ICONE, Anaheim, CA, 2012

38. J. Krepel, S. Pelloni, K. Mikityuk, P. Coddington, EQL3D: ERANOS based equilibrium fuel cycle procedure for fast reactors, Ann. Nucl. Energy 36, 550 (2009)

39. M. Aufiero, A. Cammi, C. Fiorina, J. Leppanen, L. Luzzi, M.E. Ricotti, An extended version of the SERPENT-2 code to investigate fuel burn-up and core material evolution of the molten salt fast reactor, J. Nucl. Mater. 441, 473 (2013)

40. E. Fridman, J. Leppanen, On the use of the serpent Monte Carlo code for few-group cross section generation, Ann. Nucl. Energy 38, 1399 (2011)

41. S. Dulla, Models and methods in the neutronics of fluid fuel reactors, Ph.D. thesis, Politecnico di Torino, 2005

42. S. Dulla, P. Ravetto, M.M. Rostagno, Neutron kinetics of fluid-fuel systems by the quasi-static method, Ann. Nucl. Energy 31, 1709 (2004)

43. D. Heuer, E. Merle-Lucotte et al., Simulation tools and new developments of the molten salt fast reactor, Contribution A0115, in Proceedings of the European Nuclear Conference ENC2010, Barcelona, Spain, 2010

44. E.A. Villarino, R.J.J. Stammler, A. Ferri, J.J. Casal, HELIOS: angularly dependent collision probabilities, Nucl. Sci. Eng. 112, 16 (1992)

45. F. Alcaro, S. Dulla, P. Ravetto, Neutronic evaluations for the EVOL molten salt reactor, Trans. Am. Nucl. Soc. 108, 927 (2013)

46. J.F. Briesmeister, MCNP4B-A General Monte Carlo N Particle Transport Code, Los Alamos Lab. Report LA-12625M, 1997

47. M. Brovchenko et al., Preliminary safety calculations to improve the design of molten salt fast reactor, in Proceedings of the International Conference PHYSOR 2012 Advances in Reactor Physics Linking Research, Industry, and Education, Knoxville, Tennessee, USA, 2012

48. J.W. Eastwood, J.G. Morgan, The FISPACT-II(12) Software Specification Document, Technical Report CEM/ 100421/SD/2, Issue 4, Culham Electromagnetics Ltd., May 2011 
49. C. Fiorina, D. Lathouwers, M. Aufiero, A. Cammi, C. Guerrieri, J.L. Kloosterman, L. Luzzi, M.E. Ricotti, Modelling and analysis of the MSFR transient behavior, Ann. Nucl. Energy 64, 485 (2014)

50. J. Leppanen, Development of a new Monte Carlo reactor physics code, Ph.D. thesis, Helsinki University of Technology, VTT Publications, 2007, 640 pp.
51. R. Rachamin, C. Wemple, E. Fridman, Neutronic analysis of SFR core with HELIOS-2, SERPENT, and DYN3D codes, Ann. Nucl. Energy 55, 194 (2013)

52. G. Rimpault, D. Plisson, J. Tommasi, R. Jacqmin, J. Rieunier, D. Verrier, D. Biron, The ERANOS code and data system for fast reactor neutronic analyses, in Proceedings of the International Conference PHYSOR 2002, Seoul, Korea, 2002

Cite this article as: Mariya Brovchenko, Jan-Leen Kloosterman, Lelio Luzzi, Elsa Merle, Daniel Heuer, Axel Laureau, Olga Feynberg, Victor Ignatiev, Manuele Aufiero, Antonio Cammi, Carlo Fiorina, Fabio Alcaro, Sandra Dulla, Piero Ravetto, Lodewijk Frima, Danny Lathouwers, Bruno Merk, Neutronic benchmark of the molten salt fast reactor in the frame of the EVOL and MARS collaborative projects, EPJ Nuclear Sci. Technol. 5, 2 (2019) 